\title{
Detecting layer height of smoke aerosols over vegetated land and water surfaces via oxygen absorption bands: hourly results from EPIC/DSCOVR in deep space
}

\author{
Xiaoguang Xu ${ }^{1,2}$, Jun Wang ${ }^{1}$, Yi Wang ${ }^{1}$, Jing Zeng ${ }^{1}$, Omar Torres ${ }^{3}$, Jeffrey S. Reid ${ }^{4}$, Steven D. Miller ${ }^{5}$, \\ J. Vanderlei Martins ${ }^{2}$, and Lorraine A. Remer ${ }^{2}$ \\ ${ }^{1}$ Department of Chemical and Biochemical Engineering, Center for Global and Regional Environmental Research, and \\ Informatics Initiative, The University of Iowa, Iowa City, Iowa 52241, USA \\ ${ }^{2}$ Joint Center for Earth Systems Technology and Department of Physics, University of Maryland Baltimore County, \\ Baltimore, Maryland 21250, USA \\ ${ }_{3}^{3}$ Atmospheric Chemistry and Dynamics Laboratory, NASA Goddard Space Flight Center, Greenbelt, Maryland 20770, USA \\ ${ }^{4}$ Marine Meteorology Division, Naval Research Laboratory, Monterey, California 93943, USA \\ ${ }^{5}$ Cooperative Institute for Research in the Atmosphere, Colorado State University, Fort Collins, Colorado 80523, USA
}

Correspondence: Jun Wang (jun-wang-1@uiowa.edu) and Xiaoguang Xu (xiaoguang-xu@uiowa.edu)

Received: 29 November 2018 - Discussion started: 21 December 2018

Revised: 20 May 2019 - Accepted: 27 May 2019 - Published: 20 June 2019

\begin{abstract}
We present an algorithm for retrieving aerosol layer height (ALH) and aerosol optical depth (AOD) for smoke over vegetated land and water surfaces from measurements of the Earth Polychromatic Imaging Camera (EPIC) onboard the Deep Space Climate Observatory (DSCOVR). The algorithm uses Earth-reflected radiances in six EPIC bands in the visible and near-infrared and incorporates flexible spectral fitting that accounts for the specifics of land and water surface reflectivity. The fitting procedure first determines AOD using EPIC atmospheric window bands (443, $551,680$, and $780 \mathrm{~nm})$, then uses oxygen $\left(\mathrm{O}_{2}\right) \mathrm{A}$ and $\mathrm{B}$ bands (688 and $764 \mathrm{~nm}$ ) to derive ALH, which represents an optical centroid altitude. ALH retrieval over vegetated surface primarily takes advantage of measurements in the $\mathrm{O}_{2} \mathrm{~B}$ band. We applied the algorithm to EPIC observations of several biomass burning events over the United States and Canada in August 2017. We found that the algorithm can be used to obtain AOD and ALH multiple times daily over water and vegetated land surface. Validation is performed against aerosol extinction profiles detected by the Cloud-Aerosol Lidar with Orthogonal Polarization (CALIOP) and against AOD observed at nine Aerosol Robotic Network (AERONET) sites, showing, on average, an error of $0.58 \mathrm{~km}$ and a bias of $-0.13 \mathrm{~km}$ in retrieved ALH and an error of 0.05 and a bias of 0.03 in retrieved AOD. Additionally, we show that the
\end{abstract}

aerosol height information retrieved by the present algorithm can potentially benefit the retrieval of aerosol properties from EPIC's ultraviolet (UV) bands.

\section{Introduction}

Aerosol vertical distribution is an important but poorly constrained variable that strongly influences how aerosol particles affect Earth's energy budget. In particular, absorption of solar radiation by smoke and dust particles can result in diabatic heating, alter atmospheric stability, and affect cloud formation and life cycle. These effects depend critically on the altitude of aerosol layers (Babu et al., 2011; Ge et al., 2014; Koch and Del Genio, 2010; Satheesh et al., 2008; Wendisch et al., 2008). Consequently, the aerosol profile factors into the magnitude and even the sign of aerosol direct and indirect effects. An accurate representation of aerosol altitude is thus essential for model prediction of weather and climate (Choi and Chung, 2014; Samset et al., 2013). The thermal signature of dust, in particular, can likewise influence the Earth's longwave budget and, through the interference of retrievals of water vapor and temperature, influence the measurement of atmospheric state (Maddy et al., 2012). Addi- 
tionally, knowledge of ALH is essential for retrieving aerosol absorption properties in the ultraviolet (UV) channels (Torres et al., 1998), aerosol microphysical properties from multiangular photopolarimetric measurements (Chowdhary et al., 2005; Waquet et al., 2009), and for atmospheric correction for ocean color remote sensing (Duforêt et al., 2007).

Despite the importance of aerosol vertical distribution, the simulation of aerosol layer height (ALH) in current climate models is subject to large inter-model variation and uncertainty (Kipling et al., 2016; Koffi et al., 2012). Although the assimilation of spaceborne lidar (e.g., CALIOP, or the Cloud-Aerosol Lidar with Orthogonal Polarization) observations can improve the prediction of vertical allocation (Zhang et al., 2011), a significant challenge remains due to the sparsity of lidar observations over space and time. Therefore, frequent satellite observations of global aerosol vertical distribution based on more abundant observation sources are critically needed.

One such source, the recently launched Deep Space Climate Observatory (DSCOVR) mission, has introduced an unprecedented opportunity to acquire ALH information multiple times daily. Launched on 11 February 2015, the DSCOVR spacecraft flies a Lissajous orbit around the SunEarth $\mathrm{L}_{1}$ Lagrangian point about 1.5 million kilometers from Earth in the direction of the Sun. While its primary payload is the plasma magnetometer that measures solar wind, DSCOVR also carries the Earth Polychromatic Imaging Camera (EPIC) to image the sunlit disk of Earth every $60-100 \mathrm{~min}$ from its stable $\mathrm{L}_{1}$ vantage point. EPIC captures its imagery at a resolution of 2048 by 2018 pixels, with about $8 \mathrm{~km}$ of pixel resolution at the disk's center. EPIC was equipped with a double-wheel filter to sequentially measure Earth-reflected solar radiance in 10 narrow bands spanning from the UV to the near-infrared (NIR) spectrum (Fig. 1a), with central wavelengths at $318,325,340,388,443,551$, 680, 688, 764, and 780 nm (Marshak et al., 2018).

As shown in Fig. 1b-c, two of EPIC's bands are located within the oxygen $\left(\mathrm{O}_{2}\right)$ "A" and "B" bands (764 and $688 \mathrm{~nm}$ ), each associated with a reference continuum band at 780 and $680 \mathrm{~nm}$, respectively. These four bands, offering spectral contrasts between absorption bands and continuum bands (known as differential optical absorption spectroscopic, or DOAS, ratios), were originally designed for determining cloud height (Yang et al., 2013). Recently, Xu et al. (2017) presented an algorithm to simultaneously retrieve aerosol optical depth (AOD) and ALH using the EPIC measurements via these four bands and, for the first time, demonstrated EPIC's promising application for determining dust plume height over ocean surfaces during daytime hours.

The present study, building upon the development of $\mathrm{Xu}$ et al. (2017) for determining dust ALH over ocean, extends the algorithm to retrieve ALH from EPIC measurements over land surfaces as well. The new developments in this study include implementing smoke aerosol optical properties, land surface characterization, and more robust strategies for the
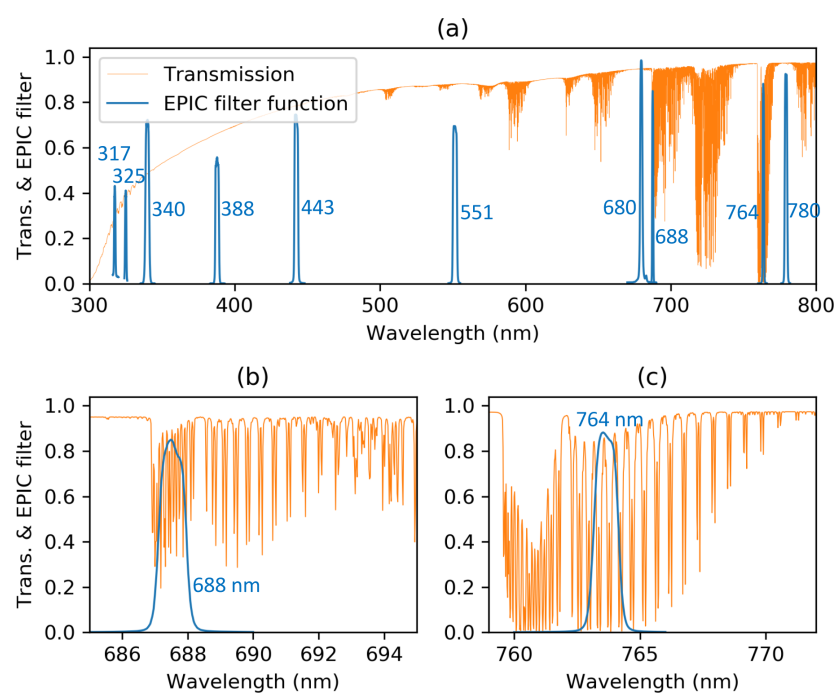

Figure 1. EPIC instrument filter response function (blue) and atmospheric spectral transmission (orange). Panel (a) includes all 10 EPIC bands, whereas panels (b) and (c) show zoomed-in views for the $688 \mathrm{~nm}$ channel in the $\mathrm{O}_{2} \mathrm{~B}$ band and the $764 \mathrm{~nm}$ channel in the $\mathrm{O}_{2} \mathrm{~A}$ band, respectively. Here the atmospheric transmission is simulated by the UNL-VRTM, with a spectral step size and a spectral full-width at half maximum of $0.02 \mathrm{~nm}$.

procedures of pixel selection and spectral fitting. The augmentation of the Xu et al. (2017) algorithm takes an important additional step towards our goal of providing more frequent global ALH and AOD information for multi-species global aerosol.

The paper is outlined as follows. Section 2 briefly reviews the physical principle for remote sensing of ALH in the $\mathrm{O}_{2}$ absorption bands and explains the challenges for retrieving ALH over land surfaces, limiting our algorithm development to water and vegetated land surface. Section 3 describes the key elements, procedures, and assumptions of the updated ALH retrieval algorithm. ALH retrievals of smoke events over Canada and the United States in August 2017 are demonstrated in Sect. 4. Section 5 evaluates the retrieved smoke ALH and AOD from EPIC against aerosol extinction profiles measured by CALIOP and AOD measured at AERONET sites. Section 6 discusses the potential application of ALH retrievals for determining UV aerosol properties. Section 7 summarizes our findings and discusses potential broader applications of this new ALH information.

\section{Remote sensing principle and challenges}

The ALH retrieval from EPIC takes advantage of the absorption features of molecular $\mathrm{O}_{2}$ in the A band at $759-771 \mathrm{~nm}$ and the B band at $686-695 \mathrm{~nm}$. The electronic transitions from the ground state to two excited states of an $\mathrm{O}_{2}$ molecule, coupled with vibrational-rotational transitions, produce $\mathrm{O}_{2}$ absorption lines in the A and B bands with distinct spectral 


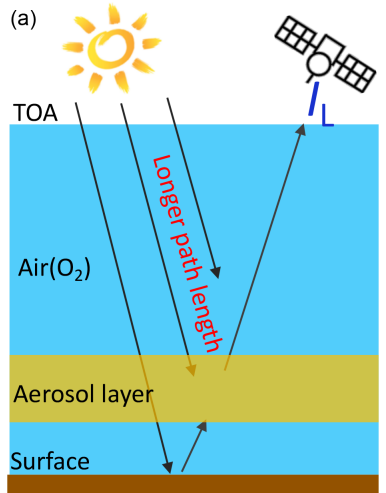

Low aerosol altitude

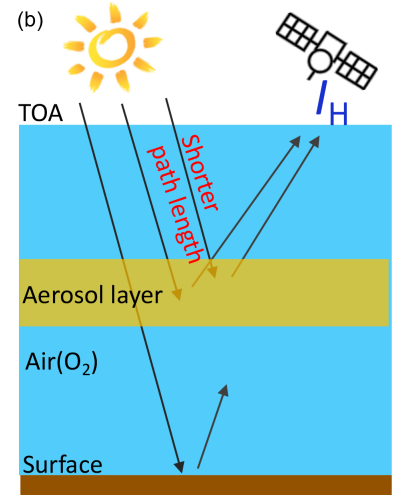

High aerosol altitude

Figure 2. Schematic diagram of the physical principle of the remote sensing of aerosol layer height in the $\mathrm{O}_{2}$ absorption bands. Shown is the same aerosol layer located at two different altitudes in the atmosphere. Due to the scattering by aerosol particles, light scattered by a higher aerosol layer (b) would travel a shorter path length to reach the satellite sensor than those scattered by the lower-altitude aerosol (a), resulting in less absorption by $\mathrm{O}_{2}$ and thus a higher radiance value detected by the satellite (i.e., $I_{\mathrm{H}}>I_{\mathrm{L}}$ ).

variability (Fig. 1b-c). As a result, the large variability of atmospheric opacity within the $\mathrm{O}_{2} \mathrm{~A}$ and $\mathrm{B}$ bands leads to a wide range of penetration depths of solar radiation (Ding et al., 2016). The spectroscopic characteristics in the $\mathrm{O}_{2}$ bands are related to how scattered light from aerosol particles interacts with $\mathrm{O}_{2}$ absorption at different altitudes. Furthermore, since $\mathrm{O}_{2}$ molecules are well mixed in the atmospheric column, the altitude dependence of $\mathrm{O}_{2}$ absorption can provide information on the path length of light scattered by aerosol particles and is thus related to the height of aerosol layers. The premise of this retrieval dates back to Hanel (1961) and Yamamoto and Wark (1961), who estimated cloud-top pressure based on the amount of absorption by molecular $\mathrm{CO}_{2}$ and $\mathrm{O}_{2}$ above the cloud layer. More recently, a number of satellite sensors have been designed to capture the $\mathrm{O}_{2}$ absorption feature to provide cloud-top height and ALH; among those are GOME, SCIAMACHY, MERIS, POLDER, DSCOVR, and most recently the TROPOspheric Monitoring Instrument (TROPOMI; Xu et al., 2018a, and references therein).

Figure 2 illustrates the physical principle for sensing ALH using the $\mathrm{O}_{2}$ absorption spectroscopic approach, which relies on the fact that a scattering aerosol layer can scatter sunlight back to space, shortening the path length of light traveling in the atmosphere and reducing the chance of that light being absorbed by $\mathrm{O}_{2}$ molecules. As a result, an elevated scattering layer enhances the top-of-atmosphere (TOA) reflectance within the $\mathrm{O}_{2}$ absorption bands as detected by a satellite. In other words, for a given aerosol layer of fixed AOD placed at different altitudes, the higher the altitude, the larger the TOA reflectance, i.e., $I_{\mathrm{H}}>I_{\mathrm{L}}$ in Fig. 2. This relationship contrasts with that of the reference continuum band, wherein

the TOA reflectance is not sensitive to the vertical location of the aerosol layer but depends only on the column AOD, i.e., $I_{\mathrm{H}} \approx I_{\mathrm{L}}$ for a given AOD. Based on this principle, the ratio of TOA reflectance between in-band and the continuum band, or the DOAS ratio, provides a practical way to infer the ALH (e.g., Dubuisson et al., 2009b; Duforêt et al., 2007; Xu et al., 2017).

To build the links between DOAS ratios and ALH, we simulate TOA reflectance as observed by EPIC measurements with the state-of-the-art Unified Linearized Vector Radiative Transfer Model (UNL-VRTM; described in Sect. 3.5). Figure 3 shows simulations of the relationship between smoke ALH ( $y$ axis) and DOAS ratios ( $x$ axis) for EPIC channels in $\mathrm{O}_{2} \mathrm{~A}$ and $\mathrm{B}$ bands and for various AOD values and surface reflectance ( $A_{\mathrm{s}}$, indicated by different colors). Those simulations were performed for a typical biomass burning aerosol model as observed by EPIC for the geometry of $\left[\theta_{0}, \theta, \Delta \phi\right]=\left[42,37,165^{\circ}\right]$, where $\theta_{0}$ and $\theta$ are solar and viewing zenith angles, and $\Delta \phi$ the relative azimuth angle between the Sun and the viewer. As seen from Fig. 3, the DOAS ratios in general increase with the rise of ALH. Meanwhile, the relationship is strongly dependent on the aerosol loading and surface reflectivity.

The sensitivity of DOAS to ALH is enhanced for lower surface reflectance and larger AOD. Conversely, the sensitivity decreases rapidly for smaller AOD (e.g., $\mathrm{AOD}=0.1$ in Fig. 3a, d) or as $A_{\mathrm{s}}$ increases, a condition under which it is difficult to discriminate between the aerosol scattering contribution to TOA reflectance and the contribution from the surface. Therefore, it is challenging to obtain ALH information for low aerosol loading conditions and over bright surfaces. This is consistent with the findings of many previous information content studies for determining ALH from $\mathrm{O}_{2}$ A and B band measurements (Ding et al., 2016; Dubuisson et al., 2009b). Duforêt et al. (2007) showed that the centroid altitude of a single aerosol layer over a dark surface can be retrieved from Polarization and Directionality of the Earth's Reflectances (POLDER) measurements with an error of less than $1 \mathrm{~km}$ when AOD is over 0.2. Similarly, Dubuisson et al. (2009b) suggested AOD $>0.3$ and $A_{\mathrm{s}}<0.06$ in order to achieve a retrieval accuracy of $0.5 \mathrm{~km}$ from POLDER.

With the above retrieval principles and challenges in mind, for our algorithm development we need to determine over what underlying Earth surfaces EPIC measurements have sufficient information to allow for a practical retrieval of ALH. First and foremost, the surface reflectance must be low enough in one of the $\mathrm{O}_{2} \mathrm{~A}$ and $\mathrm{B}$ bands to provide an unambiguous signal from the aerosol. According to Fig. 3, the DOAS-ALH sensitivity becomes substantial when $A_{\mathrm{s}}<$ 0.1 in moderate aerosol loading conditions (i.e., $\tau_{680}=0.4$ ). Hence, $A_{\mathrm{s}}=0.1$ is set as the upper threshold, above which an ALH retrieval will not be attempted, despite the sensitivity increases in high aerosol loading (e.g., $\tau_{680}=1.0$ ) for higher $A_{\mathrm{s}}$. 


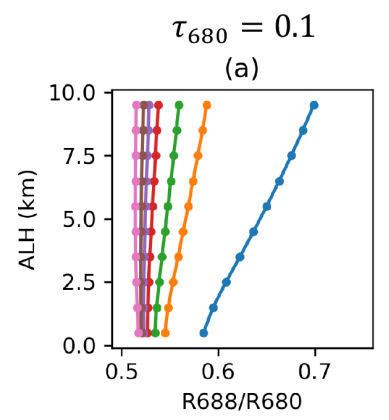

(d)

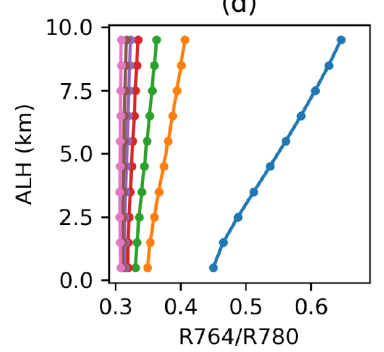

$\tau_{680}=0.4$

(b)

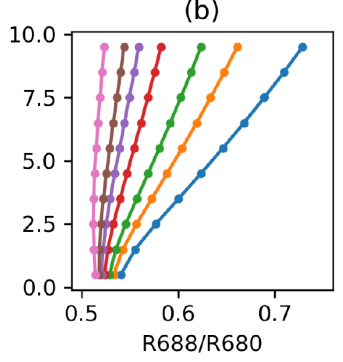

(e)

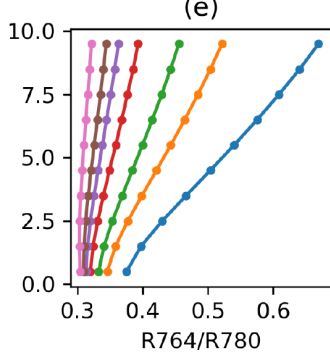

$\tau_{680}=1.0$

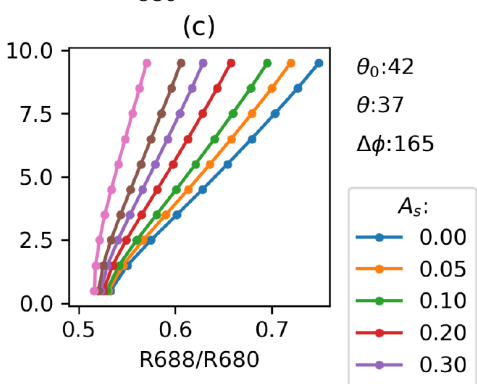

(f)

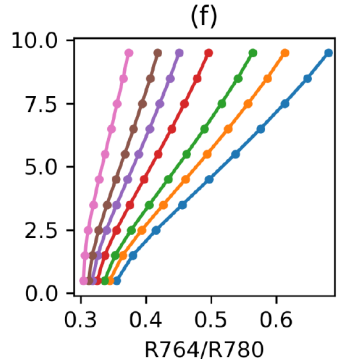

Figure 3. Sensitivity of DOAS ratios of TOA reflectance around the $\mathrm{O}_{2}$ A and B bands to smoke ALH as simulated by UNL-VRTM for different AOD and surface reflectance $\left(A_{\mathrm{S}}\right)$ values. Simulations were performed for a typical biomass burning aerosol model as observed by EPIC for the geometry of $\left[\theta_{0}, \theta, \Delta \phi\right]=\left[42,37,165^{\circ}\right]$, where $\theta_{0}$ and $\theta$ are solar and viewing zenith angles, and $\Delta \phi$ the relative azimuth angle.

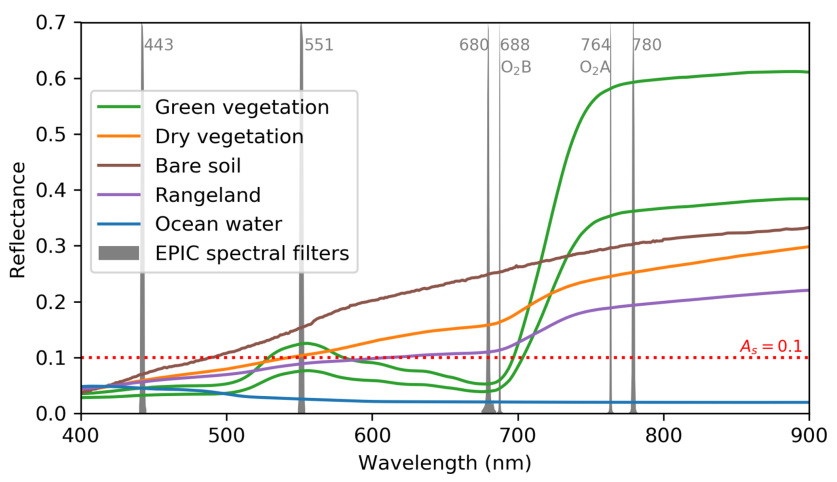

Figure 4. Surface reflectance spectra (from the ASTER spectral library; Baldridge et al., 2009) for various surface types in the visible to NIR range, with selected EPIC spectral bands within this range shown in gray.

Figure 4 shows the magnitude of surface reflectance from the ASTER spectral library for typical Earth surface types (Baldridge et al., 2009). The water surface is dark, with reflectance lower than 0.03 in both the $\mathrm{O}_{2} \mathrm{~A}$ and $\mathrm{B}$ bands. Over land, green vegetation is the only surface type that offers a reflectance below 0.1 in the $\mathrm{O}_{2} \mathrm{~B}$ band $\left(A_{\mathrm{S}}=0.1\right.$ is indicated by the red dotted line). In fact, $A_{\mathrm{s}}$ in the $\mathrm{O}_{2} \mathrm{~A}$ band is considerably above 0.1 for all land types considered in Fig. 4. These findings provide important guidance on the ALH algorithm design. Specifically, EPIC can retrieve ALH only over water and vegetated surfaces. In particular, ALH retrieval over vegetated surface would enlist DOAS ratios in the $\mathrm{O}_{2}$
B band. Additionally, retrieval of ALH requires a sufficiently high aerosol loading. We set AOD thresholds for retrieving ALH over both the water and vegetation per the algorithm overview to follow.

\section{EPIC aerosol layer height retrieval algorithm}

\subsection{Algorithm overview}

Figure 5 illustrates the processing of EPIC data and the ALH retrieval procedure. Briefly, the retrieval algorithm entails the following steps.

1. Calculate TOA reflectance in six EPIC visible and NIR bands $(443,551,680,688,764$, and $780 \mathrm{~nm})$ from the calibrated EPIC level 1B digital data.

2. Identify EPIC pixels that are suitable for aerosol height retrieval. Through various tests, this step screens out pixels having clouds, over-water sun glints, and bright land surfaces, which are performed separately for water and land pixels. Surface pressure comes from MERRA2 reanalysis data and we determine surface reflectance in EPIC bands using GOME-2 and Moderate-resolution Imaging Spectroradiometer (MODIS) surface products.

3. Aggregate the original EPIC pixels into a box of $3 \times 3$ individual pixels, an area with a size of about $24 \mathrm{~km}$ at nadir. In many cases, not all pixels within a box are suitable for retrieval (i.e., cloud, glint, and bright land). If 


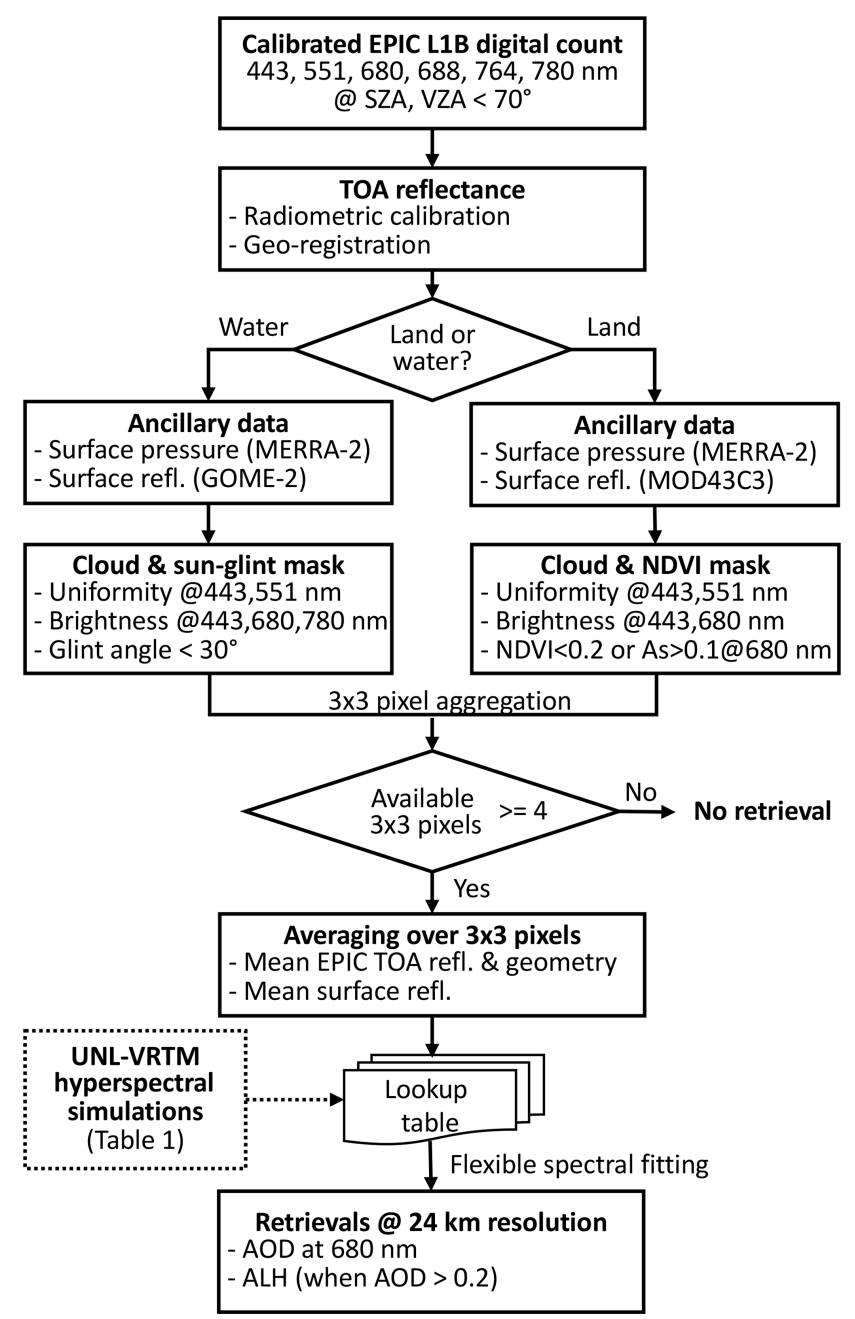

Figure 5. Flowchart of the AOD-ALH retrieval algorithm.

the number of available pixels within a box is not less than four (of the total of nine), calculate mean values of TOA reflectance, satellite geometries, and surface reflectance for the available pixels. Otherwise, do not conduct an aerosol retrieval for the box.

4. Invert the aggregated EPIC observations using precalculated lookup tables to obtain smoke ALH and AOD. The inversion uses a flexible spectral fitting strategy that considers the specific surface type.

While the retrieval procedure is based on our algorithm for retrieving dust ALH over ocean from EPIC measurements (Xu et al., 2017), it was upgraded in several ways. First, the algorithm is extended to retrieve ALH over vegetated land surface. The capability of inferring ALH over vegetation is predicated on the $\mathrm{O}_{2} \mathrm{~B}$ band, where the surface reflectance is sufficiently low. Accordingly, the new algorithm uses methods separated for land and water surfaces in determining surface reflectance and screening cloud. Second, the algorithm incorporates a smoke aerosol optical model in order to re- trieve biomass burning smoke ALH. Third, rather than aggregating EPIC data from satellite pixels to regular latitudelongitude grids, the new algorithm retrieves over aggregated boxes, each consisting of an array of $3 \times 3$ EPIC pixels. This change is based on the consideration that the geolocation of EPIC data has made significant improvements in the new version of level 1B data (Geogdzhayev and Marshak, 2018). Lastly, to obtain AOD and ALH the new algorithm employs a flexible spectral fitting strategy by considering the underlying surface reflectivity. In the following procedural subsections, we describe these changes in full detail.

\subsection{Obtaining EPIC TOA reflectance}

For this algorithm development, we used the EPIC level 1B (L1B) version 02 imagery data, available from NASA's Atmospheric Science Data Center (ASDC) at https://eosweb. larc.nasa.gov (last access: 26 November 2018). Various prelaunch and postlaunch calibrations were applied to the L1B EPIC data. EPIC visible and near-IR (NIR) channels at 443, 551, 680, and $780 \mathrm{~nm}$ were cross-calibrated with independent LEO satellite instruments, including the MODIS onboard the Terra and Aqua satellites (Geogdzhayev and Marshak, 2018). The two $\mathrm{O}_{2}$ absorption channels (688 and $764 \mathrm{~nm}$ ) were calibrated using lunar surface reflectivity with EPIC lunar observations at the time of full moon as seen from Earth (Ohtake et al., 2010). The image data in EPIC L1B products are in digital units of counts per second that are converted into reflectance for each visible and NIR channel using calibration factors provided at ASDC online: https://eosweb.larc.nasa.gov/project/dscovr/DSCOVR EPIC_Calibration_Factors_V02.pdf (last access: 26 November 2018). The TOA reflectance values are calculated as

$R_{\lambda}=\frac{K(\lambda) C(\lambda)}{\mu_{0}}$,

where $C(\lambda)$ is the EPIC measured signal in units of counts per second at the wavelength of $\lambda, K(\lambda)$ is a calibration factor, and $\mu_{0}$ is the cosine of solar zenith angle, $\theta_{0}$. Additionally, pixels that are far from nadir and strongly distorted by the Earth ellipsoid (e.g., view zenith angle $\theta>70^{\circ}$ or solar zenith angle $\theta_{0}>70^{\circ}$ ) are excluded.

\subsection{Determining surface albedo and pressure}

Past studies show that an accurate ALH retrieval critically depends on the appropriate assumption of surface reflectance (Corradini and Cervino, 2006; Ding et al., 2016; Dubuisson et al., 2009a). As discussed in the preceding section, our retrievals are confined to water and dark vegetated surfaces. Land and water mask information for each EPIC pixel was determined using the GSHHG coastline database (Wessel and Smith, 1996). Following Xu et al. (2017), surface reflectance over water surface was obtained from the GOME2 surface Lambert-equivalent reflectivity (LER) database 
(Koelemeijer et al., 2003; Tilstra et al., 2017). GOME-2 LER products contain spectral LER albedo at 21 channels that are $1 \mathrm{~nm}$ wide, available globally for each month of the year at $0.25^{\circ} \times 0.25^{\circ}$ grid spacing $(\sim 25 \times 25 \mathrm{~km}$ cells $)$. From these data, we selected LER albedos at 440, 555, 670, 758, and $780 \mathrm{~nm}$ to represent surface reflectance for the nearest EPIC bands.

The Moderate-resolution Imaging Spectroradiometer (MODIS) BRDF/Albedo product (MCD43) provides parameters that can be used to determine surface reflectance over land in the first seven MODIS channels (Lucht et al., 2000; Schaaf et al., 2002). Those parameters, including surface bidirectional reflectance distribution function (BRDF) and albedos, were inverted from the atmospherically corrected (i.e., Rayleigh and aerosol components removed) MODIS reflectance observations from both the Terra and Aqua satellites over a $16 \mathrm{~d}$ period. We used black-sky albedo and white-sky albedo compiled in the level 3 daily Climate Modeling Grid (CMG) Albedo Product (MCD43C3) at a spatial resolution of $0.1^{\circ} \times 0.1^{\circ}$. Here, black-sky albedo is the directional hemispherical reflectance if the illumination comes only from the Sun at solar noon. White-sky albedo is the bi-hemispherical reflectance under isotropic skylight illumination. The actual bi-hemispherical reflectance can be computed from white-sky and black-sky albedos via a weighting coefficient that depends primarily on solar angle and columnar optical depth (Kokhanovsky et al., 2005; Lewis and Barnsley, 1994; Schaaf et al., 2002). Following Kokhanovsky et al. (2005), we calculated the Lambertian surface albedo in the 469, 555, 645, and $858 \mathrm{~nm}$ MODIS bands by weighting the contributions of white-sky and black-sky albedos. It should be noted that the effect of nonLambertian surface reflection may bias the ALH retrieval because uncertainty in surface reflectance can substantially affect the ALH retrieval accuracy (see Appendix A). Nevertheless, this type of impact could be limited as EPIC's Earth observations are confined within an almost constant viewing geometry with scattering angles between 165 and $178^{\circ}$. Further studies are needed to examine the detailed impacts, which will be one of our future efforts.

The differences in the spectral position and width of corresponding EPIC and MODIS channels may result in discrepancies. To compensate, we adjust MODIS reflectance values to equivalent EPIC bands. The adjustment factors, in the form of linear regression coefficients, were determined from analyzing USGS (United States Geological Survey) hyperspectral data for green vegetation. Figure 6a shows the selected reflectance spectra of 47 vegetation samples from the USGS Spectral Library version 7 (Kokaly et al., 2017) and the spectral locations of EPIC (blue) and MODIS (red dotted) bands. The linear regression of reflectance values in each EPIC band and corresponding MODIS band is illustrated as scatterplots in Fig. 6c-h. The regression slope and offset, as well as coefficient of determination $\left(R^{2}\right)$, are listed in Fig. $6 \mathrm{~b}$. As shown, the reflectances between EPIC bands and their closest MODIS bands are highly correlated ( $R^{2}$ from 0.96 to 1.0 ), and therefore the best-fitting equations in Fig. $6 \mathrm{~b}$ can be used to empirically derive EPIC surface reflectance from MODIS surface reflectance products.

The retrieval also requires auxiliary meteorological information to realistically characterize $\mathrm{O}_{2}$ absorption properties. Surface pressure strongly affects the reflectance in $\mathrm{O}_{2}$ absorption bands as observed from space because it is a direct proxy for the columnar loading of air (and thus oxygen) molecules. Here, we enlisted surface pressure information from the Modern-Era Retrospective analysis for Research and Applications version 2 (MERRA-2) datasets (Gelaro et al., 2017). MERRA-2's 1-hourly surface pressure at $0.5^{\circ}$ by $0.675^{\circ}$ grids were interpolated to the location and scan time of each EPIC pixel. In addition, the atmospheric temperature-pressure profile also impacts the width and strength of $\mathrm{O}_{2}$ absorption lines. However, such an influence on the radiative transfer is negligible for EPIC's 1 to $2 \mathrm{~nm}$ wide bands. In this study, our algorithm employs a standard temperature-pressure profile representing the midlatitude summer atmosphere (McClatchey et al., 1972).

\subsection{Masking clouds, sun glints, and bright land surface}

After acquiring EPIC TOA reflectance and surface reflectance, the algorithm conducts a masking exercise to select clear-sky pixels suitable for aerosol retrieval. This includes the screenings of clouds, sun glint over water surfaces, and highly reflective land surfaces. Over both land and water, the cloud mask combines a set of brightness and homogeneity tests following Martins et al. (2002). The brightness tests screen out cloud pixels for which EPIC TOA reflectance in two or three visible bands (443 and $680 \mathrm{~nm}$ over land; 443 , 680 , and $780 \mathrm{~nm}$ over water) exceeds prescribed thresholds. The homogeneity test, on the other hand, identifies cloud pixels by evaluating the standard deviation of TOA reflectance at 443 and $551 \mathrm{~nm}$ within $3 \times 3$ neighboring pixels. Still, thin and small subpixel clouds can be missed in the relatively coarse resolution $8 \mathrm{~km}$ EPIC pixels, leading to an overestimation of AOD and an underestimation of ALH. Therefore, contamination by small-scale clouds is one of the known issues of retrieval quality, and coupling higher-resolution cloud mask information from geostationary sensors may help to overcome this issue.

In addition, EPIC pixels affected by sun glint and highly reflective land surface are also removed from consideration by the mask. We identify the over-water glint area as those pixels having a glint angle smaller than $30^{\circ}$ (Levy et al., 2013). Highly reflective land surface pixels are identified using MODIS land surface products. Any EPIC pixel having a normalized difference vegetation index (NDVI) value below 0.2 or having a $680 \mathrm{~nm}$ surface reflectance larger than 0.1 is flagged as being a bright surface and excluded from the retrievals. 


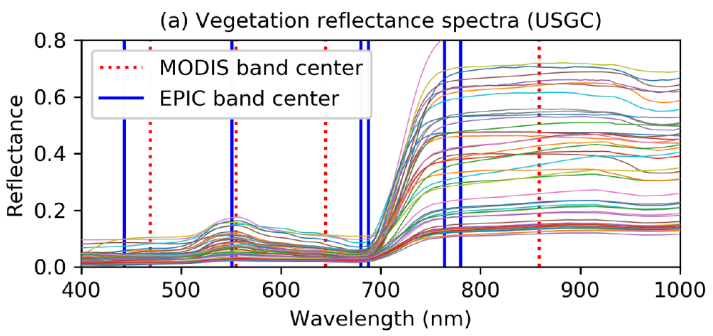

(c)

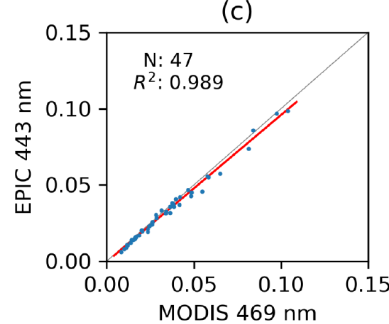

(f)

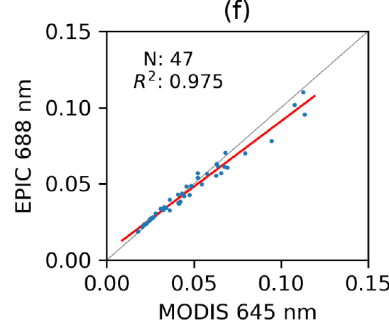

(d)

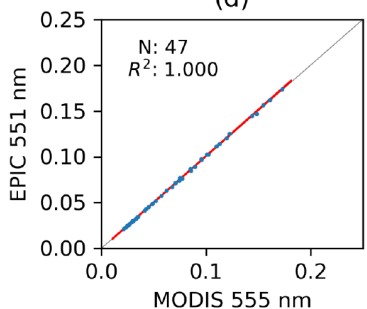

(g)

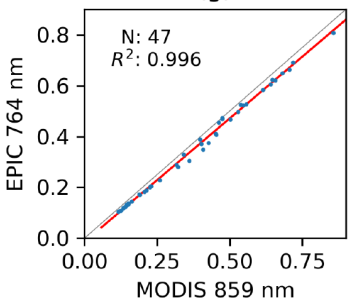

(b) Linear regression coefficients

\begin{tabular}{|c|c|c|c|}
\hline EPIC vs MODIS & Slope & Offset & $R^{2}$ \\
\hline $443 \mathrm{~nm}$ vs $469 \mathrm{~nm}$ & 0.96 & $-3.5 \mathrm{e}-04$ & 0.989 \\
\hline $551 \mathrm{~nm}$ vs $555 \mathrm{~nm}$ & 1.01 & $-4.1 \mathrm{e}-04$ & 1.000 \\
\hline $680 \mathrm{~nm}$ vs $645 \mathrm{~nm}$ & 0.81 & $2.3 \mathrm{e}-03$ & 0.962 \\
\hline $688 \mathrm{~nm}$ vs $645 \mathrm{~nm}$ & 0.86 & $5.3 \mathrm{e}-03$ & 0.975 \\
\hline $764 \mathrm{~nm}$ vs $859 \mathrm{~nm}$ & 0.97 & $-1.4 \mathrm{e}-02$ & 0.996 \\
\hline $780 \mathrm{~nm}$ vs $859 \mathrm{~nm}$ & 0.99 & $-1.3 \mathrm{e}-02$ & 0.998 \\
\hline
\end{tabular}

(e)

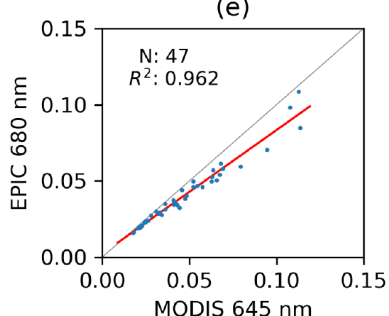

(h)

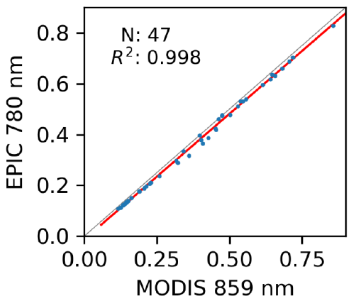

Figure 6. Determination of surface reflectance from MODIS surface albedo products. (a) USGS reflectance spectra for different vegetation samples and (b) statistics for regression (i.e., slope, offset, and coefficient of determination, $R^{2}$ ) of reflectance between different EPIC bands, marked as red dotted lines in (a), and the respective closest MODIS bands, marked as blue lines in (a), according to the spectral library. (c-f) Scatterplots of reflectance in each EPIC band versus reflectance in the corresponding MODIS bands. Linear regression lines are shown in red.

\subsection{Lookup tables}

Following Xu et al. (2017), the revised algorithm retrieves smoke ALH and AOD from EPIC measurements via a set of lookup tables (LUTs) constructed using the UNLVRTM. The UNL-VRTM (https://unl-vrtm.org, last access: 15 June 2019) is a radiative transfer test bed developed specifically for atmospheric remote sensing (Wang et al., 2014). By integrating the VLIDORT vector radiative transfer model (Spurr, 2006) and particulate scattering codes (Spurr et al., 2012), UNL-VRTM can perform simulations for two or more sets of aerosol microphysical properties, typically with aerosols in one fine mode and one coarse mode. It also incorporates HITRAN spectroscopic gaseous absorption with up to 22 trace gases (Rothman et al., 2013), allowing for accurate hyperspectral simulations of remote sensing observations (Xu et al., 2018b).

The LUTs for the current retrieval consist of simulated EPIC TOA reflectance at selected spectral bands for a set of AOD and ALH values under various atmospheric and observation scenarios (e.g., Sun-Earth-sensor geometry, surface reflectance, and surface pressure) as shown in Table 1 . To build the LUTs, hyperspectral monochromatic radiances
Table 1. Adopted parameters for generating LUTs.

\begin{tabular}{ll}
\hline Parameter $^{\mathrm{a}}$ & Prescribed values for LUTs \\
\hline AOD at $680 \mathrm{~nm}$ & $0.0,0.1,0.2,0.4,0.7,1.0,1.5$, \\
& 2.0, and 3.0 \\
ALH above surface $(\mathrm{km})$ & 0 to $15 \mathrm{~km}$ at $1 \mathrm{~km}$ interval \\
Surface reflectance & $0,0.05,0.1,0.2,0.3,0.4$, and \\
& 0.6 \\
$\theta_{0}$ and $\theta\left(^{\circ}\right)$ & 0 to $72^{\circ}$ at an interval of $6^{\circ}$, and \\
$\Delta \varphi\left(^{\circ}\right)$ & $\left|\theta_{0}-\theta\right|<15^{\circ}$ \\
Surface pressure $(\mathrm{hPa})$ & 0 to $180^{\circ}$ at an interval of $12^{\circ}$, \\
\end{tabular}

${ }^{\text {a }} \theta_{0}$ indicates the solar zenith angle, $\theta$ the satellite viewing zenith angle, and $\Delta \varphi$ the relative azimuth angle.

were simulated using UNL-VRTM and convolved with EPIC instrumental filter response functions for the selected six bands. Table 2 provides the spectral range, interval, and resolution (in terms of full-with at half maximum; FWHM) of the UNL-VRTM simulations.

The UNL-VRTM simulations assume a Gaussian-like aerosol profile characterized by a centroid altitude and a half- 
Table 2. Spectral settings of UNL-VRTM for constructing the LUTs.

\begin{tabular}{lrrr}
\hline $\begin{array}{l}\text { EPIC channel } \\
(\mathrm{nm})\end{array}$ & $\begin{array}{r}\text { Spectral range } \\
(\mathrm{nm})\end{array}$ & $\begin{array}{r}\text { Spectral interval } \\
(\mathrm{nm})\end{array}$ & $\begin{array}{r}\text { FWHM } \\
(\mathrm{nm})\end{array}$ \\
\hline 443 & $440-445$ & 0.1 & 0.2 \\
551 & $549-555$ & 0.1 & 0.2 \\
680 & $675-685$ & 0.1 & 0.2 \\
688 & $685-690$ & 0.01 & 0.02 \\
764 & $760-766$ & 0.01 & 0.02 \\
780 & $776-782$ & 0.1 & 0.2 \\
\hline
\end{tabular}

width parameter (Spurr and Christi, 2014; Xu et al., 2017). The centroid altitude is taken to represent ALH. A half-width of $1 \mathrm{~km}$ is assumed following Xu et al. (2017). This value was also used to derive AOD from UV observations by the Total Ozone Mapping Spectrometer (TOMS) and the Ozone Monitoring Instrument (OMI) (Torres et al., 1998). For this study, we implemented smoke optical properties calculated based on the Lorenz-Mie scattering theory. The smoke refractive index was assumed to be $1.5-0.012 i$, following Dubovik et al. (2002), and its spectral dependence was neglected. We assumed smoke particles followed a bi-lognormal size distribution, as adopted for the MODIS dark-target aerosol algorithm (Levy et al., 2013; Remer et al., 2005). Specifically, fine-mode volume median radius and standard deviation were prescribed as $0.14+0.01 \tau_{680} \mu \mathrm{m}$ and 0.44 , respectively. The coarse-mode counterparts are $0.14+0.01 \tau_{680} \mu \mathrm{m}$ and 0.80 , respectively. The volume ratio between fine and coarse modes is $\left(0.01+0.3 \tau_{680}\right) /\left(0.01+0.09 \tau_{680}\right)$. Here, $\tau_{680}$ is the total AOD at $680 \mathrm{~nm}$.

\subsection{Strategy of flexible spectral fitting}

The retrieval procedure involves two steps over both water and land surfaces and, at the same time, incorporates flexible spectral fitting that accounts for the specifics of surface reflectivity. First, the TOA reflectance in the EPIC "atmospheric window" channels are matched with LUTs to determine AOD, since the TOA reflectance does not depend on ALH in these channels. Second, based on this estimated AOD, the DOAS ratios around the $\mathrm{O}_{2}$ bands are fitted to estimate ALH. In each step, least-squared fitting is applied, and fitting residuals are reported.

In general, retrieving aerosol information from reflected solar radiation in visible to NIR wavelengths over land is more challenging than over ocean, since the satellite signal tends to be dominated by surface contributions over land. It is thus often the case that, for the same satellite instrument, separate over-land and over-ocean algorithms are developed with different strategies for characterizing surface reflectivity and band selection for fitting, e.g., MODIS aerosol algorithms (Remer et al., 2005). Similarly, our retrieval of smoke ALH from EPIC uses different band combinations over land versus over ocean, adjusted by surface type and the spectral signature of smoke aerosol in the TOA reflectance.

In general, reflectance of water surfaces does not exceed 0.03 across the entire visible to NIR spectrum (Fig. 4). Therefore, AOD can be determined by fitting TOA reflectance in all four atmospheric window channels at $443,551,680$, and $780 \mathrm{~nm}$. In contrast, the $780 \mathrm{~nm}$ band is excluded for spectral fitting over vegetated land surface because of the high chlorophyll reflectance. Similarly, in the fitting of DOAS ratios, different weights are given for the ratios in the $\mathrm{O}_{2} \mathrm{~A}$ and $\mathrm{B}$ bands for different surfaces, adjusted by the sensitivity of the DOAS ratio to ALH (e.g., Fig. 3). The weighting coefficients are 0.4 for $R 688 / R 680$ and 0.6 for $R 764 / R 780$ over water surface, whereas these values are 0.9 and 0.1 over vegetated surface.

\section{Retrieval demonstration}

We apply our algorithm to six EPIC scenes over the Hudson Bay-Great Lakes area obtained during 25-26 August 2017, with three consecutive scenes considered on each day. We chose these cases primarily because smoke plumes prevailed over both water and vegetated surface, and there were available aerosol vertical profile measurements from CALIOP that could be used to validate the ALH retrievals. As shown in the EPIC RGB images (Figs. 7a and 8a), smoke aerosols appeared as diffuse plumes emitted from wildfires in western Canada and transported over the western and southern portions of Hudson Bay (Peterson et al., 2018). The retrieved smoke ALH is shown in Figs. $7 \mathrm{~b}$ and $8 \mathrm{~b}$, and retrieved $680 \mathrm{~nm}$ AOD in Figs. 7c and 8c. It is noted that data gaps in the AOD maps represent screened-out bright pixels due to either cloud or bright land surface; ALH retrievals were only available when AOD was larger than 0.2.

Obvious spatial variations are noted in retrieved smoke ALH and AOD. On 25 August, smoke plumes had AOD values ranging from 0.1 to 0.45 , with higher loading found at downwind regions in the south (Fig. 7c). An ALH of 4-5 km was found over Hudson Bay, whereas the smoke altitudes decreased to 2-4 km over land off the bay's western and southern shores (Fig. 7b). Southward, the ALH increased rapidly to 4-6 km towards the Great Lakes. By 26 August, the smoke plumes had traveled southeast (Fig. 8c). The smoke altitudes remained at $3-5 \mathrm{~km}$ over the eastern part of Hudson Bay and $2-4 \mathrm{~km}$ over the bay's south side (Fig. 8b). Altitudes of smoke plumes over the coast of the northeastern US were higher than $5 \mathrm{~km}$. Aside from spatial variations, the retrievals also revealed diurnal changes in ALH and the evolution of the smoke plumes. For instance, the ALH of smoke plumes over the Hudson Bay and the north side of the Great Lakes rose by about $0.5 \mathrm{~km}$ within $2 \mathrm{~h}$ from local morning to afternoon on 25 August (Fig. 7b). 


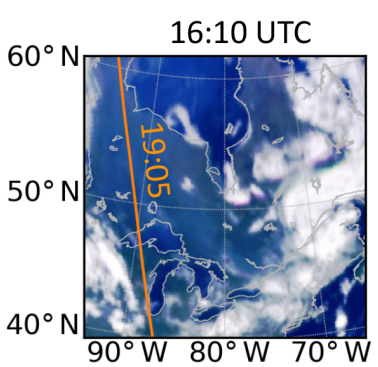

(a) EPIC RGB

$17: 26$ UTC

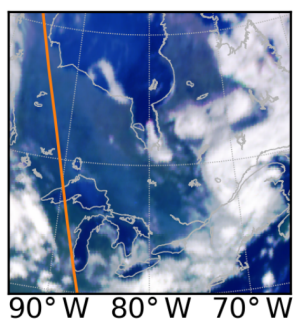

$18: 32$ UTC

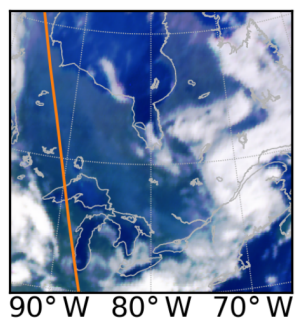

(b) EPIC-retrieved ALH (km)
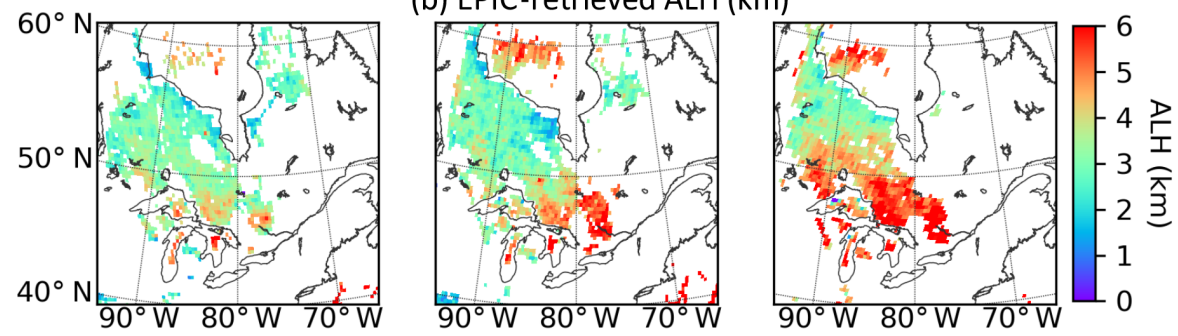

(c) EPIC-retrieved $680 \mathrm{~nm}$ AOD
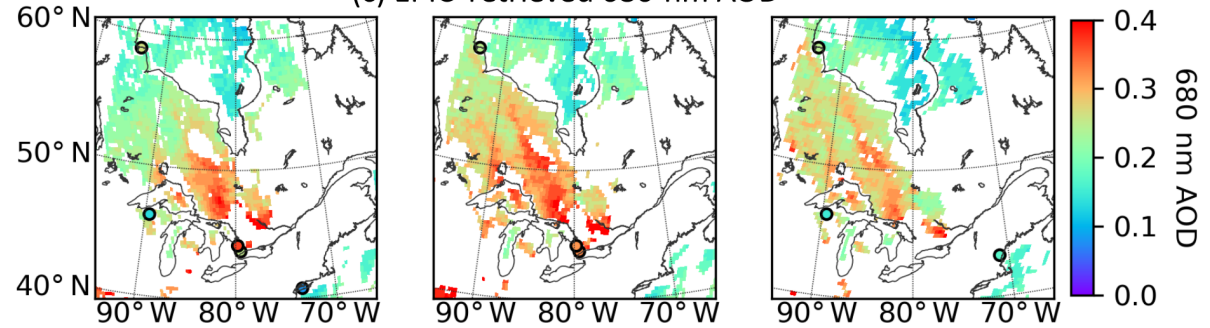

Figure 7. Demonstration of ALH and AOD retrievals for three EPIC scenes acquired on 25 August 2017 around UTC times of 16:10, 17:26, and 18:32. (a) Red-green-blue (RGB) composites of EPIC 443, 551, and $680 \mathrm{~nm}$ data. The gold line indicates the CALIOP sub-orbital track with an overpass time of 19:05 UTC. (b) Retrieved smoke ALH when $680 \mathrm{~nm}$ AOD is larger than 0.2. (c) Retrieved 680 nm AOD. Small circles on AOD maps represent AOD values observed at corresponding AERONET sites within $2 \mathrm{~h}$ of the EPIC scan time.

\section{Retrieval validation}

For the validation of the EPIC-retrieved ALH, we used CALIOP level 2 version 4.10 aerosol extinction profiles at $5 \mathrm{~km}$ spatial resolution, retrieved from CALIOP observations of attenuated backscatter at $532 \mathrm{~nm}$ (Young and Vaughan, 2009). To facilitate quantitative comparison of aerosol altitude, we used a mean extinction height calculated from the CALIOP extinction profile, following Koffi et al. (2012):

$\mathrm{ALH}_{\mathrm{CALIOP}}=\frac{\sum_{i=1}^{n} \beta_{\mathrm{ext}, i} Z_{i}}{\sum_{i=1}^{n} \beta_{\mathrm{ext}, i}}$.

Here, $\beta_{\text {ext }, i}$ is the aerosol extinction coefficient $\left(\mathrm{km}^{-1}\right)$ at $532 \mathrm{~nm}$ at level $i$, and $Z_{i}$ is the altitude $(\mathrm{km})$ of level $i$. Thus, $\mathrm{ALH}_{\mathrm{CALIOP}}$ represents an effective ALH weighted by the aerosol extinction signal at each level and is consistent with ALH as defined in our EPIC algorithm.

In the CALIOP level 2 products, aerosol extinction is only retrieved for the layers in which aerosols are detected, as permitted by the instrument's signal-to-noise ratio (SNR). Atmospheric layers with no aerosols detected are classi- fied as "clear air" and assigned an aerosol extinction coefficient of $0 \mathrm{~km}^{-1}$. The detection limits are defined in terms of backscattering ratio, which depends on an aerosol lidar ratio (Vaughan et al., 2009). As such, aerosol layers that span a large altitude range frequently remain undetected (Toth et al., 2018), particularly for absorbing aerosols in the daytime. As indicated by Winker et al. (2013), the aerosol extinction threshold in a daytime CALIOP scan is $0.01-0.03 \mathrm{~km}^{-1}$ for $80 \mathrm{~km}$ horizontal averaging resolution and increases to $0.07 \mathrm{~km}^{-1}$ for $5 \mathrm{~km}$ horizontal averaging resolution. In reality, aerosols are ubiquitous throughout the troposphere, though the concentration can be very low in the free troposphere. However, excluding the clear-air layers would lead to a biased estimate of $\mathrm{ALH}_{\mathrm{CALIOP}}$, particularly for cases of predominantly clear-air layers present below an elevated aerosol layer. To compensate for this bias, we use an exponentially decayed background aerosol extinction profile to provide a proxy for the aerosol extinction coefficients of these undetected aerosol layers within the troposphere. The background profile has a columnar AOD of about 0.07 at $532 \mathrm{~nm}$ according to Tomasi and Petkov (2014), who use 


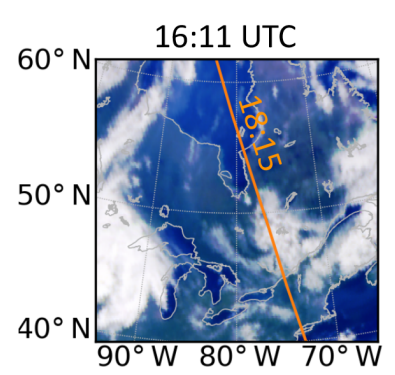

(a) EPIC RGB

17:17 UTC

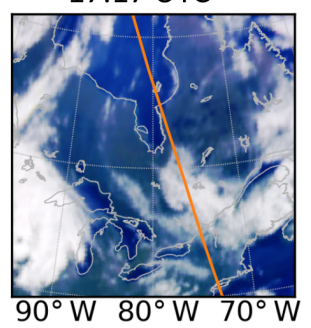

(b) EPIC-retrieved ALH ( $\mathrm{km})$
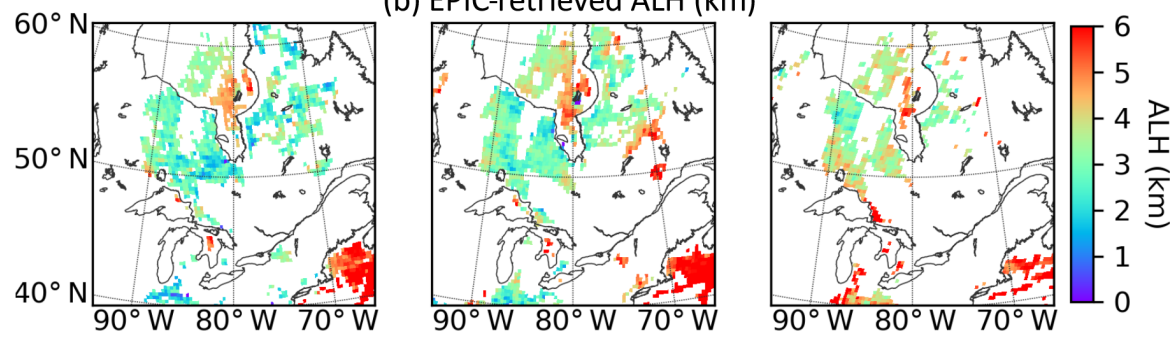

(c) EPIC-retrieved $680 \mathrm{~nm}$ AOD
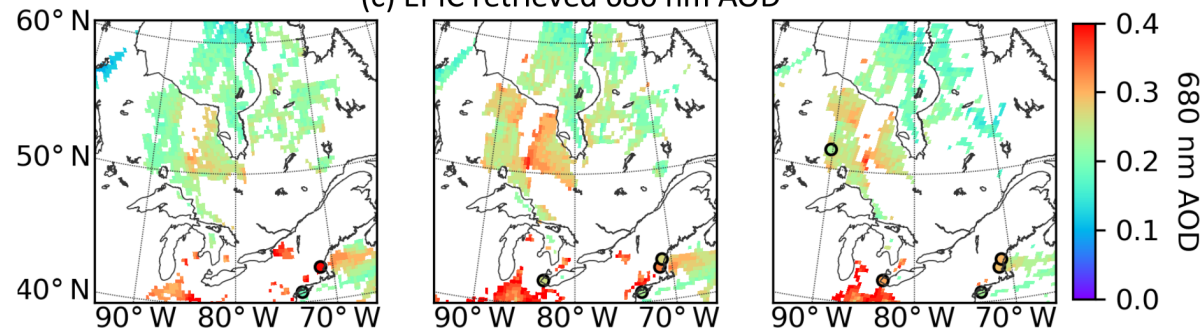

Figure 8. Same as Fig. 7 but for three EPIC scenes captured on 26 August 2017 at UTC times of 16:11, 17:17, and 18:22. The CALIOP overpass was at 18:15 UTC.

various lidar measurements to characterize the summertime Arctic atmosphere. Though aerosol extinction within the undetected aerosol layers by no means follows the background extinction profile identically, adding such a background aerosol extinction profile could, to the first order, correct the potential bias in $\mathrm{ALH}_{\mathrm{CALIOP}}$. Therefore, we consider $\mathrm{ALH}_{\mathrm{CALIOP}}$ with and without the imposed background aerosol in the following validation analysis.

Figure 9 presents the evaluation of our ALH retrieval against CALIOP observations, showing that the ALH retrieval captures the overall spatial variability of ALH as seen by CALIOP. Quantitatively, $67 \%$ and $59 \%$ of the retrievals are within $0.5 \mathrm{~km}$ of difference from the counterparts of $\mathrm{ALH}_{\mathrm{CALIOP}}$ on 25 and 26 August, respectively. Considering all EPIC-CALIOP ALH pairs, over $65 \%$ of ALH retrievals are within an uncertainty envelope of $0.5 \mathrm{~km}$ (Fig. 10a-b), and EPIC ALH has a mean bias of $-0.13 \mathrm{~km}$ and a root mean square error (RMSE) of $0.58 \mathrm{~km}$, capturing $52 \%$ of the variation of $\mathrm{ALH}_{\mathrm{CALIOP}}$ (Fig. 10a). If background aerosol is imposed in the CALIOP ALH calculation, our retrieved EPIC ALH is found to have a bias of $0.23 \mathrm{~km}$ and an RMSE of $0.57 \mathrm{~km}$ (Fig. 10b).
Table 3. AERONET sites selected for AOD validation.

\begin{tabular}{lrrr}
\hline Site name & Latitude $\left(^{\circ}\right)$ & Longitude $\left(^{\circ}\right)$ & $N_{\text {AOD }}^{\mathrm{a}}$ \\
\hline Billerica & 42.53 & -71.27 & 3 \\
Churchill & 58.74 & -93.82 & 3 \\
Egbert & 44.23 & -78.78 & 2 \\
Lake_Erie & 41.83 & -83.19 & 2 \\
LISCO & 40.76 & -73.34 & 4 \\
NEON_UNDE & 46.23 & -89.54 & 2 \\
Pickle_Lake & 51.45 & -90.22 & 1 \\
Thompson_Farm & 43.11 & -70.95 & 3 \\
Toronto & 43.79 & -79.47 & 2 \\
\hline
\end{tabular}

${ }^{\text {a }} N_{\mathrm{AOD}}$ is the number of collocated AERONET AOD values.

The EPIC $680 \mathrm{~nm}$ AOD retrievals during the two days were compared against $675 \mathrm{~nm}$ AOD observations at nine AERONET sites (Table 3). The collocation method follows Ichoku et al. (2002) but was modified to compare EPIC AOD retrievals over $3 \times 3$ pixels centered at the AERONET sites with $1 \mathrm{~h}$ AERONET AOD observations around the EPIC scan time. Collocated AERONET AOD values at each site are 
(a)

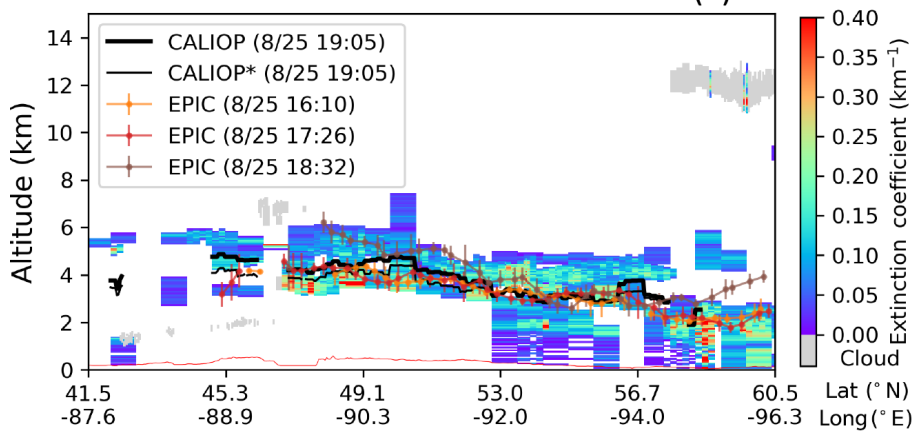

(c)

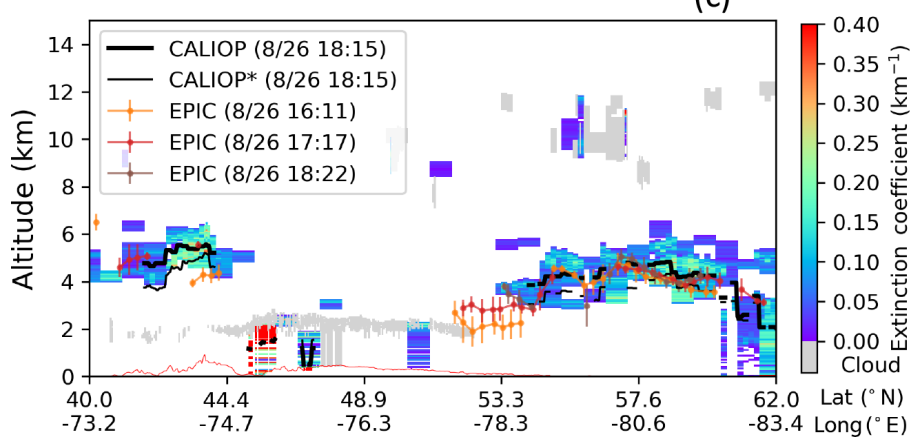

(b)

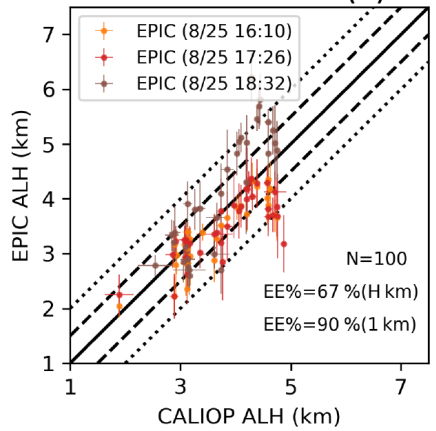

(d)

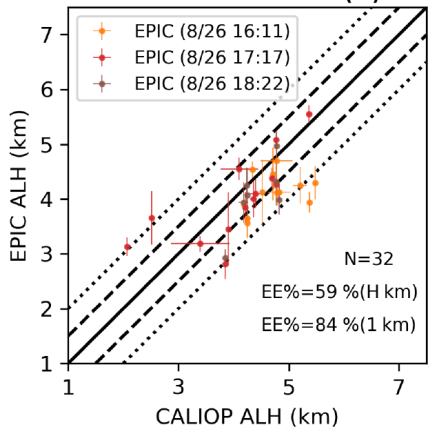

Figure 9. Comparison of ALH retrieved from EPIC and CALIOP level 2 aerosol extinction profile in both "curtain" view (a, c) and "scatterplot" view $(\mathbf{b}, \mathbf{d})$ for $2 \mathrm{~d}$ overpasses. The CALIOP orbital tracks are marked on EPIC RGB images in Figs. 7-8. Different EPIC scan times are marked with different line and symbol colors in the comparison. The error bar for EPIC ALH represents the standard deviation for an array of $3 \times 324 \mathrm{~km}$ retrieval pixels, while that for CALIOP ALH represents the standard deviation of over five adjacent CALIOP $5 \mathrm{~km}$ footprints. Also shown in panels $(\mathbf{a}, \mathbf{c})$ is the CALIOP* ALH (thin black curve) calculated with a background aerosol profile imposed for undetected aerosol layers (see text for detail), whereas the bold black curve represents the CALIOP ALH without considering background aerosol.

(a)

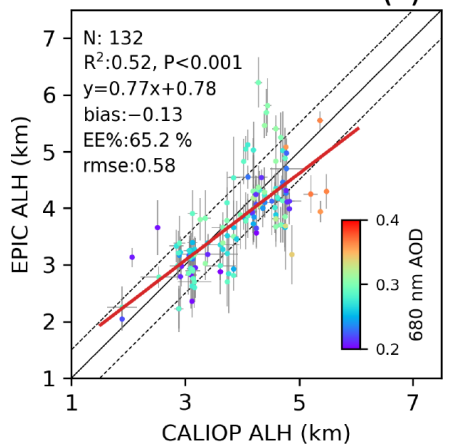

(b)

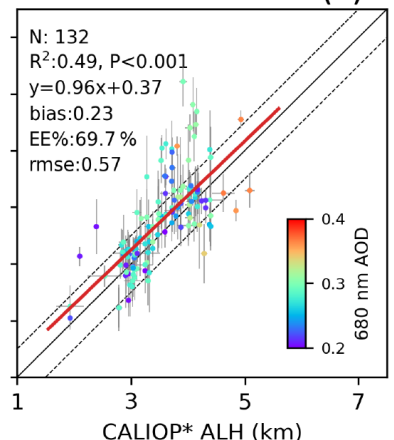

(c)

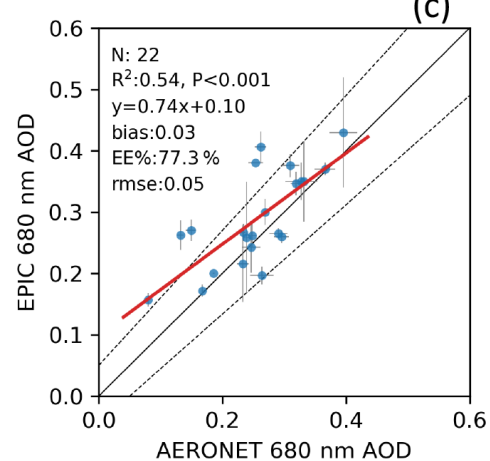

Figure 10. Comparison of EPIC ALH and AOD with the corresponding CALIOP and AERONET measurements. (a) Scatterplot of EPIC ALH versus CALIOP ALH by including all EPIC-CALIOP pairs shown in Fig. 9. The color of each scatter point represents the EPIC $680 \mathrm{~nm}$ AOD value for the same EPIC pixels. (b) Same as panel (a) but for CALIOP ALH calculated with a background aerosol profile imposed for undetected aerosol layers. (c) Scatterplot of EPIC $680 \mathrm{~nm}$ AOD versus AERONET $675 \mathrm{~nm}$ AOD, collocated at the nine AERONET sites listed in Table 3. The dotted lines in both the scatterplots represent error envelops, i.e., $\pm 0.5 \mathrm{~km}$ for ALH and $\pm(0.05+10 \%)$ for AOD. Also annotated are the one-to-one line (solid black line), linear regression fit (red line), number of scatter points $(N)$, coefficient of determination $\left(R^{2}\right)$, significance level $(P)$, linear regression equation, bias, percentage of scatter points within the error envelop (EE \%), and root mean square error (RMSE). 


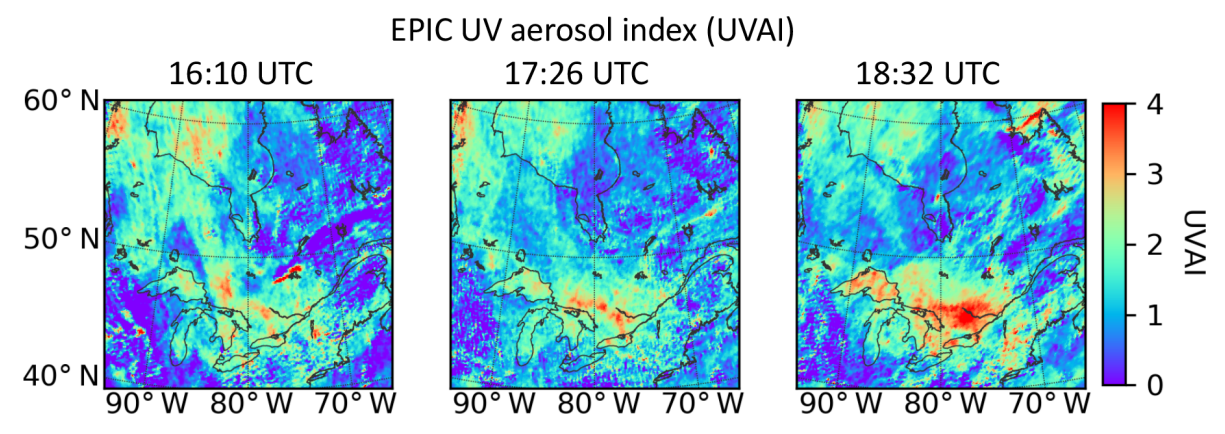

Figure 11. EPIC UV aerosol index (UVAI) for the three scenes on 25 August 2017 shown in Fig. 7. Here the UVAI was obtained from EPIC level 2 UV aerosol products.

shown as circles in Figs. 7c and 8c. A comparison of EPIC and AERONET AODs is shown in Fig. 10c. The collocated AOD pairs, though with limited data samplings, have over $77 \%$ falling in an uncertainty envelope of $\pm(0.05+0.1 \mathrm{AOD})$ with a coefficient of determination $\left(R^{2}\right)$ of 0.54 . The EPIC AOD shows a positive bias of 0.03 and an RMSE of 0.05 , which was dominated by four subsets of EPIC AODs and was likely caused by cloud contamination.

\section{Implication to the retrieval of UV absorbing aerosol properties}

One important implication of this study is that the retrieved ALH can provide complementary height information for determining absorbing aerosol properties from EPIC's UV bands. EPIC also measures backscattered UV radiances at 340 and $388 \mathrm{~nm}$, which was designed to detect and retrieve the optical properties of UV-absorbing aerosols like mineral dust and smoke by using the UV aerosol index (UVAI) (Marshak et al., 2018). UVAI quantifies the difference in spectral dependence between measured and calculated near-UV radiances assuming a purely molecular atmosphere (Torres et al., 1998). Physically, inferring aerosol properties from those UV bands requires the characterization of aerosol height, since UV radiance is sensitive to aerosol vertical distribution. For example, Jeong and Hsu (2008) retrieved aerosol single-scattering albedo (SSA) from OMI radiance via synergic use of AOD from MODIS and ALH from CALIOP. Currently, EPIC's UV aerosol algorithm utilizes a climatological aerosol height dataset derived from CALIOP observations (Torres et al., 2013). However, these static climatological data may fail to capture the dynamic variation of aerosol height and thus induce uncertainties in the UVretrieved aerosol properties. With the aerosol height and loading available from EPIC's $\mathrm{O}_{2} \mathrm{~A}$ and $\mathrm{B}$ bands, these closures are now possible with measurements from a single instrument. Such synergy can be also applied to the TROPOspheric Monitoring Instrument (TROPOMI) and the Plankton, Aerosol, Cloud, ocean Ecosystem (PACE) satellite, both of which obtain hyperspectral measurements from the UV to the NIR covering the $\mathrm{O}_{2} \mathrm{~A}$ and $\mathrm{B}$ bands (Omar et al., 2018; Veefkind et al., 2012).

Here, we compare our retrieved ALHs with EPIC UVAI to illustrate the importance, as well the potential benefit, of the ALH retrievals to EPIC's UV aerosol products. The EPIC UVAI data are publicly available at https://eosweb.larc.nasa. gov/project/dscovr/ (last access: 26 November 2018). Figure 11 shows the UVAI of the same EPIC scenes on $25 \mathrm{Au}-$ gust. These smoke plumes are highlighted by large values of UVAI, which are in contrast to clouds that typically exhibit a UVAI close to zero (Torres et al., 1998). Since UVAI is a function of ALH, AOD, and SSA, its correlation with ALH varies with AOD. As shown in Fig. 12, the sensitivity of UVAI to ALH, as well as the correlation between them, increases as AOD increases. In particular, high AOD values (e.g., over 0.4) may result in UVAI values from less than 1 to about 4, depending on the ALH (Fig. 12, bottom right panel). Therefore, the use of ALH derived from the EPIC $\mathrm{O}_{2}$ bands is expected to improve EPIC UV aerosol retrievals.

\section{Summary and discussion}

We extend our retrieval algorithm for retrieving over-water dust ALH from EPIC measurements (Xu et al., 2017) to biomass burning smoke aerosols over both water and vegetated land surfaces. The new algorithm uses Earth-reflected radiances in EPIC's visible and NIR bands and incorporates flexible spectral fitting that accounts for the specifics of vegetation and water surface reflectivity. The fitting procedure first determines AOD using four EPIC atmospheric window bands $(443,551,680$, and $780 \mathrm{~nm})$ and then uses the DOAS ratios formulated in the $\mathrm{O}_{2} \mathrm{~A}$ and $\mathrm{B}$ bands (688 and $764 \mathrm{~nm}$ ) to derive the ALH that represents an optical centroid altitude. ALH retrieval over vegetated surface primarily takes advantage of the measurements in the $\mathrm{O}_{2} \mathrm{~B}$ band, where surface reflectance is sufficiently low to yield aerosol height information. Surface reflectance values are specified using MODIS surface products over land and GOME-2 LER products over ocean. 

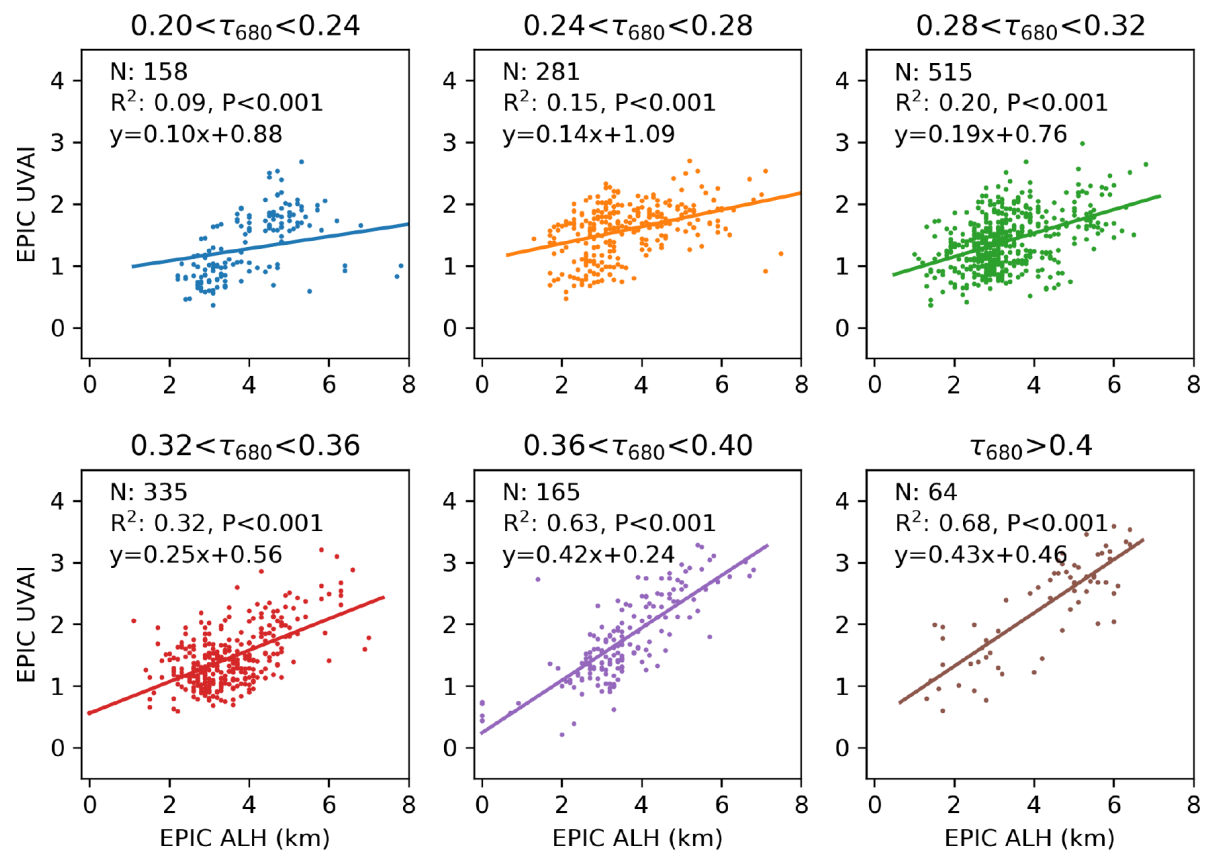

Figure 12. Scatterplots of EPIC UVAI (Fig. 11) versus current retrievals of ALH (Fig. 7) on 25 August 2017 (17:26 UTC) under different AOD values as indicated in the title of each panel. Also annotated are the linear regression fit, number of scatter points $(N)$, coefficient of determination $\left(R^{2}\right)$, and significance level $(P)$.

We applied the algorithm to six EPIC images, with three images on each day, having biomass burning plumes over the United States and Canada acquired on 25-26 August 2017. The algorithm is able to retrieve AOD and ALH multiple times daily over both water and vegetated land surfaces. The retrieved ALHs were validated against CALIOP extinctionweighted aerosol height $\left(\mathrm{ALH}_{\mathrm{CALIOP}}\right)$, showing that EPICretrieved ALH has an RMSE of $0.58 \mathrm{~km}$ and captures $52 \%$ of the variation of $\mathrm{ALH}_{\mathrm{CALIOP}}$, and $65 \%$ of EPIC and CALIOP ALH pairs are within an uncertainty envelope of $0.5 \mathrm{~km}$. EPIC-retrieved AODs are validated against AERONET AOD observed at nine sites, indicating an RMSE of 0.05, and over $77 \%$ of EPIC AOD retrievals fall within the error envelope of $\pm(0.05+0.1 \mathrm{AOD})$. In addition, by comparing the retrieved ALH and EPIC UVAI, we show that the aerosol height information retrieved by the present algorithm can potentially benefit the retrieval of aerosol properties from the EPIC UV bands.

Over 3 years of data recorded thus far by EPIC (July 2015-present) offer an opportunity to characterize aerosol height from diurnal to seasonal scales. Such datasets with well-characterized uncertainties are valuable for evaluating aerosol vertical distribution simulated by climate models. A follow-on study, based on the current work and $\mathrm{Xu}$ et al. (2017), will examine the long-term global retrieval of ALH for dust and smoke aerosols. Challenges for such a global retrieval include the heterogeneity of aerosol species, whereas our efforts have been mainly focused on singlespecies (dust or smoke) aerosol assumptions. In fact, mix- tures of aerosol are more commonly found in nature. Furthermore, the currently available EPIC UVAI products can help identify elevated absorbing aerosols (mainly dust and smoke), which can then be used to determine the retrieval targets on any EPIC image.

Data availability. The data presented in this paper can be obtained by emailing the corresponding authors (Xiaoguang $\mathrm{Xu}$ and Jun Wang). 


\section{Appendix A: Sensitivity and error analysis}

In this Appendix, we investigate the sensitivity of EPIC measurements in the $\mathrm{O}_{2} \mathrm{~A}$ and $\mathrm{B}$ bands to the aerosol vertical profile shape, aerosol optical properties, and surface reflectance assumed in the retrieval algorithm. Then, we estimate potential ALH retrieval errors due to the uncertainties in these parameters. For this case, ALH is derived from two DOAS ratios $(\rho)$ in the $\mathrm{O}_{2} \mathrm{~A}$ and B bands. Mathematically, the retrieval error $(\hat{\epsilon})$ of ALH can be estimated using the optimal estimation approach (Xu and Wang, 2015):

$\hat{\epsilon}^{-2}=\mathbf{K}^{\mathrm{T}} \mathbf{S}_{\epsilon}^{-1} \mathbf{K}$

where $\mathbf{K}$ is the Jacobian matrix of $\rho$ with respect to ALH, and $\mathbf{S}_{\epsilon}$ is the observation error covariance matrix for $\rho$. In this study, we assume no error correlation between the two DOAS ratios. That is, $\mathbf{S}_{\epsilon}$ is a diagonal matrix with its elements equal to the error variance for $\rho$. Observation error variance matrix $\mathbf{S}_{\epsilon}$ can be characterized as a sum of two terms:

$\mathbf{S}_{\epsilon}=\mathbf{S}_{\rho}+\mathbf{S}_{\mathrm{m}}$.

Here, $\mathbf{S}_{\rho}$ is the error covariance matrix describing the uncertainty for EPIC measurements. $\mathbf{S}_{\mathrm{m}}$ is the covariance matrix for forward model errors caused by inaccurate model assumptions and uncertainties in model parameterizations, and $\mathbf{S}_{\mathrm{m}}$ can be calculated by

$\mathbf{S}_{\mathrm{m}}=\mathbf{K}_{b}^{\mathrm{T}} \mathbf{S}_{b} \mathbf{K}_{b}$,

where $\mathbf{S}_{b}$ is the error covariance matrix describing uncertainties of the vector of model parameters $\boldsymbol{b}$, and $\mathbf{K}_{b}$ is Jacobian matrix of $\rho$ with respect to $\boldsymbol{b}$. In the following analysis, we consider four parameters for the vector $\boldsymbol{b}$, i.e., the half-width parameter $\left(\sigma_{\mathrm{H}}\right)$ defining the quasi-Gaussian aerosol vertical profile, the $680 \mathrm{~nm}$ AOD $\left(\tau_{680}\right)$, aerosol single-scattering albedo (SSA), and surface reflectance $A_{\mathrm{s}}$.

Figure A1 presents the UNL-VRTM-simulated DOAS ratios $\rho$ in the EPIC $\mathrm{O}_{2} \mathrm{~A}$ and B band (panel a) and their Jacobian gradients with respect to ALH (panel b) and with respect to the abovementioned four model parameters (panels $\mathrm{c}-\mathrm{f}$ ) for the vector $\boldsymbol{b}$ for various surface and aerosol loading conditions. Figure A2 shows the estimated ALH retrieval errors owing to EPIC observation error and uncertainties in the assumed model parameters for water (with $A_{\mathrm{s}}=0.05$ in both $\mathrm{O}_{2} \mathrm{~A}$ and $\mathrm{B}$ bands) and vegetation (with $A_{\mathrm{s}}=0.30$ in the $A$ band and 0.05 in the B band) surfaces. The findings from these Jacobian and error analysis results can be summarized as follows.

- The sensitivity of $\rho$ with respect to ALH (Fig. A1b) is weak for aerosols confined in the lower atmosphere (ALH below $1.5 \mathrm{~km}$ ). The sensitivity increases rapidly with the increase in ALH, peaks for ALH about $4 \mathrm{~km}$, and then deceases slightly for higher elevated aerosols. The sensitivity in the $\mathrm{O}_{2} \mathrm{~A}$ band is stronger than that in the $\mathrm{O}_{2} \mathrm{~B}$ band, and it is stronger for low surface reflectance and high aerosol loading. By considering $2 \%$ uncertainty for the EPIC DOAS ratios (Geogdzhayev and Marshak, 2018), the ALH retrieval error $\left(\hat{\epsilon}_{0}\right)$ is less than $0.5 \mathrm{~km}$ for the water surface and is less than $0.75 \mathrm{~km}$ for the vegetated surface if ALH is over $1.5 \mathrm{~km}$ (black curves in Fig. A2a-b). This error characterization is consistent with the retrieval error $(0.57-0.58 \mathrm{~km})$ as estimated through the validation with CALIOP data.

- The DOAS ratios $\rho$ have a negative sensitivity to $\sigma_{\mathrm{H}}$ for elevated aerosol, and the sensitivity turns to positive for ALH below $1.5 \mathrm{~km}$ (Fig. A1c). An error of $0.5 \mathrm{~km} \sigma_{\mathrm{H}}$ may cause up to $0.3 \mathrm{~km}$ of retrieval error for ALH (blue curves in Fig. A2c-d).

- The DOAS ratios $\rho$ have a positive sensitivity to $\tau_{680}$, and the sensitivity increases as ALH increases (Fig. A1d). An error of 0.05 in $\tau_{680}$ can lead to a retrieval error from 0 to $0.6 \mathrm{~km}$ for ALH, depending on the aerosol loading and surface type (orange curves in Fig. A2c-d).

- DOAS ratios are sensitive to SSA to some degree, especially for large AOD values (Fig. A1e). However, the sensitivity to SSA is much less significant than the sensitivity to AOD and surface reflectance because the reflectance at TOA depends more on surface reflectance and AOD (than SSA in a relative sense). As a result, SSA only has a marginal impact on the ALH retrieval error (green curves in Fig. A2c-d), which is consistent with findings by Sanders et al. (2015).

- The DOAS ratio $\rho$ has a negative sensitivity to $A_{\mathrm{s}}$, and the sensitivity increases as ALH increases (Fig. A1f). An error of 0.01 in $A_{\mathrm{S}}$ can result in a retrieval error of $0.1-0.6 \mathrm{~km}$ for ALH over water surface and $0.1-0.4 \mathrm{~km}$ over vegetation surface, depending on the aerosol loading (purple curves in Fig. A2c-d).

- If including possible uncertainties from these four parameters in vector $\boldsymbol{b}$ and EPIC measurement error, the estimated ALH retrieval errors $\left(\hat{\epsilon}_{\mathrm{All}}\right)$ are shown as red curves in Fig. A2a-b. For elevated smoke aerosols with $\tau_{680}=0.4, \hat{\epsilon}_{\text {All }}$ ranges from 0.4 to $1.0 \mathrm{~km}$ for water surface and from 0.7 to $1.25 \mathrm{~km}$ for vegetation surface; the $\hat{\epsilon}_{\text {All }}$ range for $\tau_{680}=1.0$ is reduced to $0.3-0.5 \mathrm{~km}$ for water and $0.4-0.6 \mathrm{~km}$ for vegetation surface. 

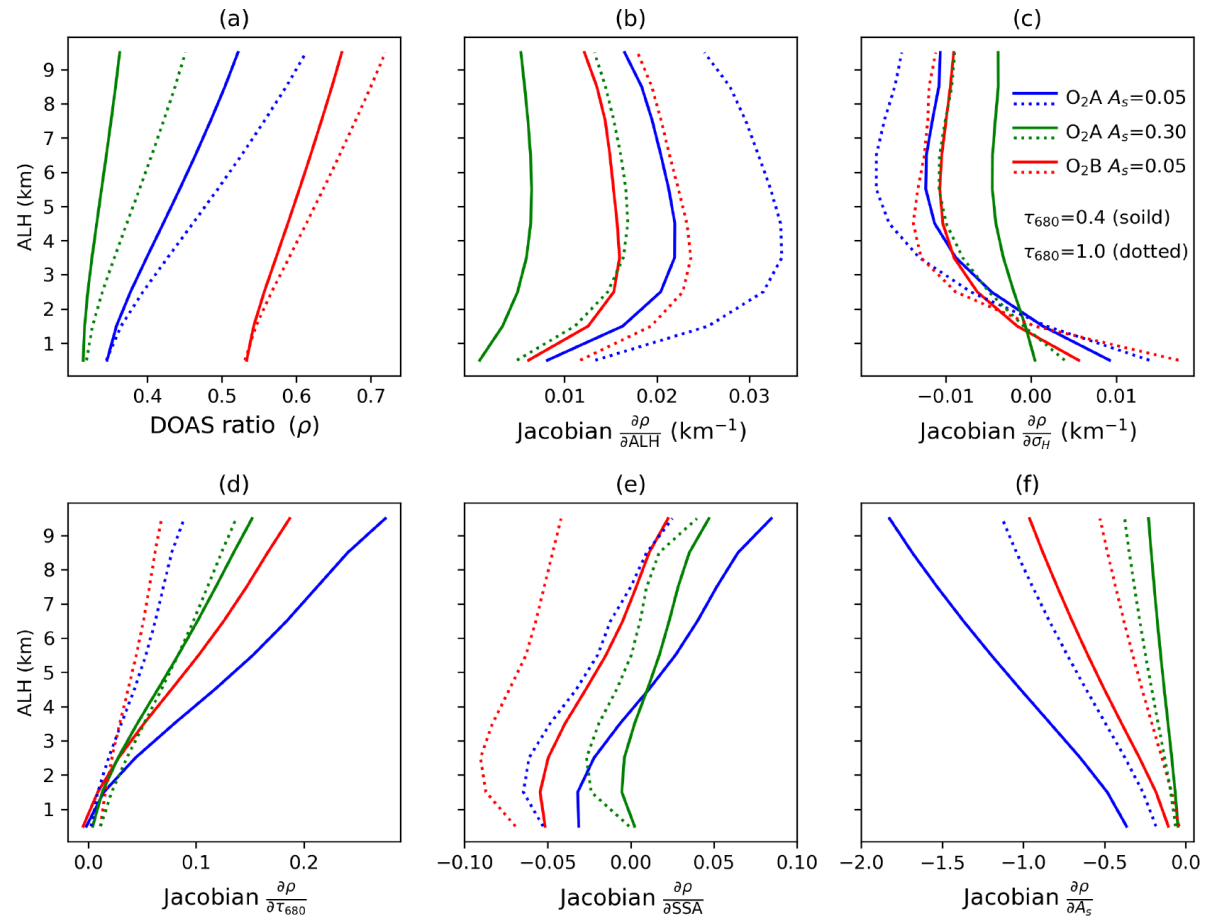

Figure A1. UNL-VRTM-simulated DOAS ratios $\rho$ in EPIC $\mathrm{O}_{2} \mathrm{~A}$ and B band (a) and their Jacobian gradients with respect to ALH (b), half-width parameter $\sigma_{\mathrm{H}}$ for the quasi-Gaussian aerosol vertical profile (c), $680 \mathrm{~nm}$ AOD $\tau_{680}(\mathbf{d})$, SSA (e), and surface reflectance $A_{\mathrm{S}}(\mathbf{f})$. The $y$ axis represents aerosols being present at various ALH values. Three colors indicate $\rho$ and its Jacobians for the $\mathrm{O}_{2}$ A band with $A_{\mathrm{S}}=0.05$ (blue), the $\mathrm{O}_{2} \mathrm{~A}$ band with $A_{\mathrm{S}}=0.30$ (green), and the $\mathrm{O}_{2} \mathrm{~B}$ band with $A_{\mathrm{S}}=0.05$ (red). Two AOD loadings are indicated by the solid $\left(\tau_{680}=0.4\right)$ and dotted $\left(\tau_{680}=1.0\right)$ lines, respectively. Simulations are performed with the same aerosol model and observation geometry in Fig. 3. 


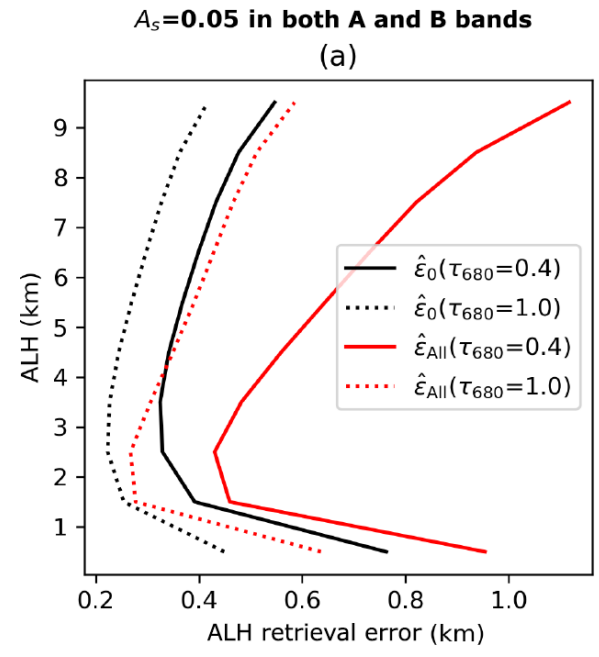

(c)

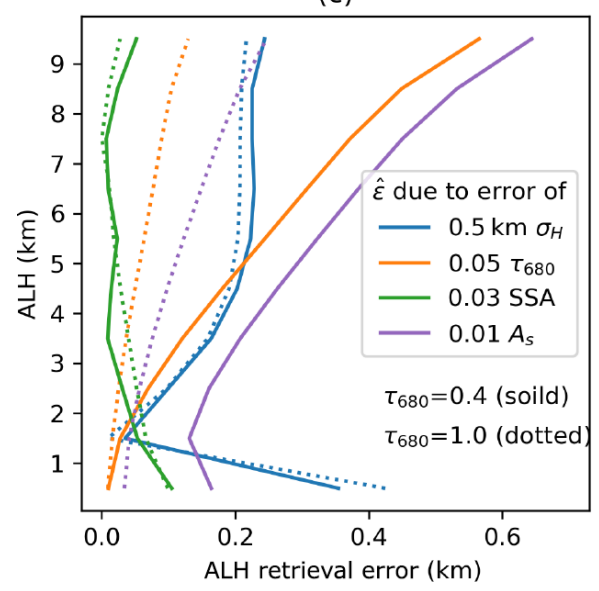

$A_{s}=0.30$ in $A$ and 0.05 in $B$ band

(b)

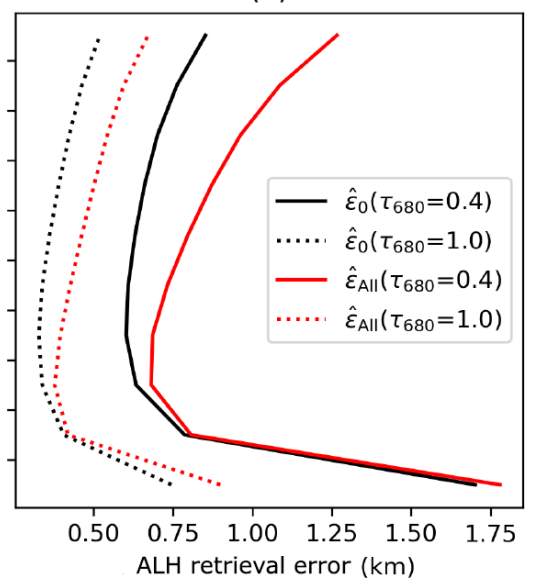

(d)

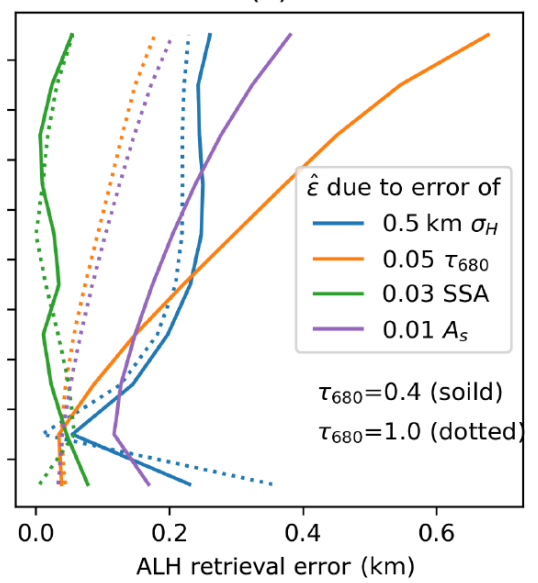

Figure A2. Estimated ALH retrieval errors owing to EPIC measurement errors and uncertainties in aerosol and surface assumptions. Panels (a) and (c) are for a surface with $A_{\mathrm{S}}=0.05$ reflectance in both the $\mathrm{O}_{2} \mathrm{~A}$ and $\mathrm{B}$ bands (close to a water surface), and panels (b) and (d) are for $A_{\mathrm{S}}=0.30$ in the $\mathrm{A}$ band and $A_{\mathrm{S}}=0.05$ in the $\mathrm{B}$ band (close to a vegetation surface). (a-b) ALH retrieval errors due to $2 \%$ EPIC measurement error alone (black curves) and with model uncertainty from all four parameters added (red curves). (c-d) The error in retrieved ALH due to uncertainty from each of the parameters: $0.5 \mathrm{~km}$ in $\sigma_{\mathrm{H}}$ (blue), 0.05 in $\tau_{680}$ (orange), 0.03 in SSA (green), and 0.01 in $A_{\mathrm{S}}$ (purple). In all panels, the solid and dotted curves represent 0.4 and $1.0 \tau_{680}$, respectively. 
Author contributions. JW and XX designed the research; XX and JW conducted the research and wrote the paper; YW contributed data analysis for validation; JZ, OT, JSR, SDM, JVM, and LAR contributed to the writing.

Competing interests. The authors declare that they have no conflict of interest.

Special issue statement. This article is part of the special issue "Holistic Analysis of Aerosol in Littoral Environments - A Multidisciplinary University Research Initiative (ACP/AMT inter-journal $\mathrm{SI})$ ". It is not associated with a conference.

Acknowledgements. This research is supported in part by the NASA DSCOVR Earth Science Algorithms Program (grant no. NNX17AB05G, managed by Richard S. Eckman) and in part by the Office of Naval Research (ONR) Multidisciplinary University Research Initiatives (MURI) program under award no. N0001416-1-2040. We acknowledge the computational support from the High-Performance Computing group at the University of Iowa and the UMBC High-Performance Computing Facility (HPCF). EPIC level 1B (L1B) version 02 imagery data are obtained from the NASA Atmospheric Science Data Center (ASDC). We also acknowledge the AERONET program for providing AOD data retrieved from sun photometers. We thank Feng $\mathrm{Xu}$ and two other anonymous reviewers for their insightful comments on the paper.

Financial support. This research has been supported by NASA (grant no. NNX17AB05G) and the Office of Naval Research (grant no. N00014-16-1-2040).

Review statement. This paper was edited by Sebastian Schmidt and reviewed by Feng $\mathrm{Xu}$ and two anonymous referees.

\section{References}

Babu, S. S., Moorthy, K. K., Manchanda, R. K., Sinha, P. R., Satheesh, S. K., Vajja, D. P., Srinivasan, S., and Kumar, V. H. A.: Free tropospheric black carbon aerosol measurements using high altitude balloon: Do BC layers build "their own homes" up in the atmosphere?, Geophys. Res. Lett., 38, L08803, https://doi.org/10.1029/2011gl046654, 2011.

Baldridge, A. M., Hook, S. J., Grove, C. I., and Rivera, G.: The ASTER spectral library version 2.0, Remote Sens. Environ., 113, 711-715, https://doi.org/10.1016/j.rse.2008.11.007, 2009.

Choi, J.-O. and Chung, C. E.: Sensitivity of aerosol direct radiative forcing to aerosol vertical profile, Tellus B, 66, 24376, https://doi.org/10.3402/tellusb.v66.24376, 2014.

Chowdhary, J., Cairns, B., Mishchenko, M. I., Hobbs, P. V., Cota, G. F., Redemann, J., Rutledge, K., Holben, B. N., and Russell, E.: Retrieval of Aerosol Scattering and Absorption Properties from Photopolarimetric Observations over the Ocean dur- ing the CLAMS Experiment, J. Atmos. Sci., 62, 1093-1117, https://doi.org/10.1175/JAS3389.1, 2005.

Corradini, S. and Cervino, M.: Aerosol extinction coefficient profile retrieval in the oxygen A-band considering multiple scattering atmosphere. Test case: SCIAMACHY nadir simulated measurements, J. Quant. Spectrosc. Ra., 97, 354-380, https://doi.org/10.1016/j.jqsrt.2005.05.061, 2006.

Ding, S., Wang, J., and Xu, X.: Polarimetric remote sensing in oxygen $\mathrm{A}$ and $\mathrm{B}$ bands: sensitivity study and information content analysis for vertical profile of aerosols, Atmos. Meas. Tech., 9, 2077-2092, https://doi.org/10.5194/amt-9-2077-2016, 2016.

Dubovik, O., Holben, B., Eck, T. F., Smirnov, A., Kaufman, Y. J., King, M. D., Tanré, D., and Slutsker, I.: Variability of Absorption and Optical Properties of Key Aerosol Types Observed in Worldwide Locations, J. Atmos. Sci., 59, 590-608, https://doi.org/10.1175/15200469(2002)059<0590:voaaop>2.0.co;2, 2002.

Dubuisson, P., Frouin, R., Dessailly, D., Duforêt, L., Léon, J.-F., Voss, K., and Antoine, D.: Estimating the altitude of aerosol plumes over the ocean from reflectance ratio measurements in the $\mathrm{O}_{2}$ A-band, Remote Sens. Environ., 113, 1899-1911, https://doi.org/10.1016/j.rse.2009.04.018, 2009a.

Dubuisson, P., Frouin, R., Dessailly, D., Duforêt, L., Léon, J.-F., Voss, K., and Antoine, D.: Estimating the altitude of aerosol plumes over the ocean from reflectance ratio measurements in the $\mathrm{O}_{2}$ A-band, Remote Sens. Environ., 113, 1899-1911, https://doi.org/10.1016/j.rse.2009.04.018, 2009b.

Duforêt, L., Frouin, R., and Dubuisson, P.: Importance and estimation of aerosol vertical structure in satellite ocean-color remote sensing, Appl. Optics, 46, 1107-1119, https://doi.org/10.1364/AO.46.001107, 2007.

Ge, C., Wang, J., and Reid, J. S.: Mesoscale modeling of smoke transport over the Southeast Asian Maritime Continent: coupling of smoke direct radiative effect below and above the low-level clouds, Atmos. Chem. Phys., 14, 159-174, https://doi.org/10.5194/acp-14-159-2014, 2014.

Gelaro, R., McCarty, W., Suárez, M. J., Todling, R., Molod, A., Takacs, L., Randles, C. A., Darmenov, A., Bosilovich, M. G., Reichle, R., Wargan, K., Coy, L., Cullather, R., Draper, C., Akella, S., Buchard, V., Conaty, A., Silva, A. M. D., Gu, W., Kim, G.K., Koster, R., Lucchesi, R., Merkova, D., Nielsen, J. E., Partyka, G., Pawson, S., Putman, W., Rienecker, M., Schubert, S. D., Sienkiewicz, M., and Zhao, B.: The Modern-Era Retrospective Analysis for Research and Applications, Version 2 (MERRA2), J. Climate, 30, 5419-5454, https://doi.org/10.1175/jcli-d-160758.1, 2017.

Geogdzhayev, I. V. and Marshak, A.: Calibration of the DSCOVR EPIC visible and NIR channels using MODIS Terra and Aqua data and EPIC lunar observations, Atmos. Meas. Tech., 11, 359368, https://doi.org/10.5194/amt-11-359-2018, 2018.

Hanel, R. A.: Determination of cloud altitude from a satellite, J. Geophys. Res., 66, 1300-1300, https://doi.org/10.1029/JZ066i004p01300, 1961.

Ichoku, C., Chu, D. A., Mattoo, S., Kaufman, Y. J., Remer, L. A., Tanré, D., Slutsker, I., and Holben, B. N.: A spatio-temporal approach for global validation and analysis of MODIS aerosol products, Geophys. Res. Lett., 29, 1616, https://doi.org/10.1029/2001GL013206, 2002. 
Jeong, M.-J. and Hsu, N. C.: Retrievals of aerosol single-scattering albedo and effective aerosol layer height for biomass-burning smoke: Synergy derived from "A-Train" sensors, Geophys. Res. Lett., 35, L24801, https://doi.org/10.1029/2008g1036279, 2008.

Kipling, Z., Stier, P., Johnson, C. E., Mann, G. W., Bellouin, N., Bauer, S. E., Bergman, T., Chin, M., Diehl, T., Ghan, S. J., Iversen, T., Kirkevåg, A., Kokkola, H., Liu, X., Luo, G., van Noije, T., Pringle, K. J., von Salzen, K., Schulz, M., Seland, Ø., Skeie, R. B., Takemura, T., Tsigaridis, K., and Zhang, K.: What controls the vertical distribution of aerosol? Relationships between process sensitivity in HadGEM3-UKCA and inter-model variation from AeroCom Phase II, Atmos. Chem. Phys., 16, 2221-2241, https://doi.org/10.5194/acp-16-2221-2016, 2016.

Koch, D. and Del Genio, A. D.: Black carbon semi-direct effects on cloud cover: review and synthesis, Atmos. Chem. Phys., 10, 7685-7696, https://doi.org/10.5194/acp-10-7685-2010, 2010.

Koelemeijer, R. B. A., de Haan, J., and Stammes, P.: A database of spectral surface reflectivity in the range 335-772 nm derived from 5.5 years of GOME observations, J. Geophys. Res., 108, 4070, https://doi.org/10.1029/2002jd002429, 2003.

Koffi, B., Schulz, M., Bréon, F.-M., Griesfeller, J., Winker, D., Balkanski, Y., Bauer, S., Berntsen, T., Chin, M., Collins, W. D., Dentener, F., Diehl, T., Easter, R., Ghan, S., Ginoux, P., Gong, S., Horowitz, L. W., Iversen, T., Kirkevåg, A., Koch, D., Krol, M., Myhre, G., Stier, P., and Takemura, T.: Application of the CALIOP layer product to evaluate the vertical distribution of aerosols estimated by global models: AeroCom phase I results, J. Geophys. Res.-Atmos., 117, D10201, https://doi.org/10.1029/2011jd016858, 2012.

Kokaly, R. F., Clark, R. N., Swayze, G. A., Livo, K. E., Hoefen, T. M., Pearson, N. C., Wise, R. A., Benzel, W. M., Lowers, H. A., Driscoll, R. L., and Klein, A. J.: USGS Spectral Library Version 7, Reston, VA, Report 1035, 68, 2017.

Kokhanovsky, A. A., Mayer, B., and Rozanov, V. V.: A parameterization of the diffuse transmittance and reflectance for aerosol remote sensing problems, Atmos. Res., 73, 37-43, https://doi.org/10.1016/j.atmosres.2004.07.004, 2005.

Levy, R. C., Mattoo, S., Munchak, L. A., Remer, L. A., Sayer, A. M., Patadia, F., and Hsu, N. C.: The Collection 6 MODIS aerosol products over land and ocean, Atmos. Meas. Tech., 6, 29893034, https://doi.org/10.5194/amt-6-2989-2013, 2013.

Lewis, P. and Barnsley, M. J.: Influence of the sky radiance distribution on various formulations of the earth surface albedo, in: Proc. Conf. Phys. Meas. Sign. Remote Sens, Val d'Isere, France, 707-715, 1994.

Lucht, W., Schaaf, C. B., and Strahler, A. H.: An algorithm for the retrieval of albedo from space using semiempirical BRDF models, Geoscience and Remote Sensing, IEEE Transactions on, 38, 977-998, https://doi.org/10.1109/36.841980, 2000.

Maddy, E. S., DeSouza-Machado, S. G., Nalli, N. R., Barnet, C. D., Strow, L., Wolf, W. W., Xie, H., Gambacorta, A., King, T. S., Joseph, E., Morris, V., Hannon, S. E., and Schou, P.: On the effect of dust aerosols on AIRS and IASI operational level 2 products, Geophys. Res. Lett., 39, L10809, https://doi.org/10.1029/2012g1052070, 2012.

Marshak, A., Herman, J., Szabo, A., Blank, K., Carn, S., Cede, A., Geogdzhayev, I., Huang, D., Huang, L.-K., Knyazikhin, Y., Kowalewski, M., Krotkov, N., Lyapustin, A., McPeters, R., Meyer, K., Torres, O., and Yang, Y.: Earth Observations from
DSCOVR/EPIC Instrument, B. Am. Meteorol. Soc., 99, 18291850, https://doi.org/10.1175/bams-d-17-0223.1, 2018.

Martins, J. V., Tanré, D., Remer, L., Kaufman, Y., Mattoo, S., and Levy, R.: MODIS Cloud screening for remote sensing of aerosols over oceans using spatial variability, Geophys. Res. Lett., 29, 1619, https://doi.org/10.1029/2001GL013252, 2002.

McClatchey, R. A., Fenn, R. W., Selby, J. E. A., Volz, F. E., and Garing, J. S.: Optical Properties of the Atmosphere (Third Edition), Air Force Cambridge Research Labs, Hanscom AFB, MA, 110 pp., 1972.

Ohtake, M., Matsunaga, T., Yokota, Y., Yamamoto, S., Ogawa, Y., Morota, T., Honda, C., Haruyama, J., Kitazato, K., Takeda, H., Iwasaki, A., Nakamura, R., Hiroi, T., Kodama, S., and Otake, H.: Deriving the Absolute Reflectance of Lunar Surface Using SELENE (Kaguya) Multiband Imager Data, Space Sci. Rev., 154, 57-77, https://doi.org/10.1007/s11214-010-9689-0, 2010.

Omar, A. H., Tzortziou, M., Coddington, O., and Remer, L. A.: Plankton Aerosol, Cloud, ocean Ecosystem mission: atmosphere measurements for air quality applications, J. Appl. Remote Sens., 12, 042608, https://doi.org/10.1117/1.JRS.12.042608, 2018.

Peterson, D. A., Campbell, J. R., Hyer, E. J., Fromm, M. D., Kablick, G. P., Cossuth, J. H., and DeLand, M. T.: Wildfiredriven thunderstorms cause a volcano-like stratospheric injection of smoke, Climate and Atmospheric Science, 1, 30, https://doi.org/10.1038/s41612-018-0039-3, 2018.

Remer, L. A., Kaufman, Y. J., Tanre, D., Mattoo, S., Chu, D. A., Martins, J. V., Li, R.-R., Ichoku, C., Levy, R. C., Kleidman, R. G., Eck, T. F., Vermote, E., and Holben, B. N.: The MODIS Aerosol Algorithm, Products, and Validation, J. Atmos. Sci., 62, 947-973, https://doi.org/10.1175/JAS3385.1, 2005.

Rothman, L. S., Gordon, I. E., Babikov, Y., Barbe, A., Chris Benner, D., Bernath, P. F., Birk, M., Bizzocchi, L., Boudon, V., Brown, L. R., Campargue, A., Chance, K., Cohen, E. A., Coudert, L. H., Devi, V. M., Drouin, B. J., Fayt, A., Flaud, J. M., Gamache, R. R., Harrison, J. J., Hartmann, J. M., Hill, C., Hodges, J. T., Jacquemart, D., Jolly, A., Lamouroux, J., Le Roy, R. J., Li, G., Long, D. A., Lyulin, O. M., Mackie, C. J., Massie, S. T., Mikhailenko, S., Müller, H. S. P., Naumenko, O. V., Nikitin, A. V., Orphal, J., Perevalov, V., Perrin, A., Polovtseva, E. R., Richard, C., Smith, M. A. H., Starikova, E., Sung, K., Tashkun, S., Tennyson, J., Toon, G. C., Tyuterev, V. G., and Wagner, G.: The HITRAN2012 molecular spectroscopic database, J. Quant. Spectrosc. Ra., 130, 4-50, https://doi.org/10.1016/j.jqsrt.2013.07.002, 2013.

Samset, B. H., Myhre, G., Schulz, M., Balkanski, Y., Bauer, S., Berntsen, T. K., Bian, H., Bellouin, N., Diehl, T., Easter, R. C., Ghan, S. J., Iversen, T., Kinne, S., Kirkevåg, A., Lamarque, J.-F., Lin, G., Liu, X., Penner, J. E., Seland, Ø., Skeie, R. B., Stier, P., Takemura, T., Tsigaridis, K., and Zhang, K.: Black carbon vertical profiles strongly affect its radiative forcing uncertainty, Atmos. Chem. Phys., 13, 2423-2434, https://doi.org/10.5194/acp13-2423-2013, 2013.

Sanders, A. F. J., de Haan, J. F., Sneep, M., Apituley, A., Stammes, P., Vieitez, M. O., Tilstra, L. G., Tuinder, O. N. E., Koning, C. E., and Veefkind, J. P.: Evaluation of the operational Aerosol Layer Height retrieval algorithm for Sentinel-5 Precursor: application to $\mathrm{O}_{2}$ A band observations from GOME-2A, Atmos. Meas. Tech., 8, 4947-4977, https://doi.org/10.5194/amt-8-49472015, 2015. 
Satheesh, S. K., Moorthy, K. K., Babu, S. S., Vinoj, V., and Dutt, C. B. S.: Climate implications of large warming by elevated aerosol over India, Geophys. Res. Lett., 35, L19809, https://doi.org/10.1029/2008GL034944, 2008.

Schaaf, C. B., Gao, F., Strahler, A. H., Lucht, W., Li, X., Tsang, T., Strugnell, N. C., Zhang, X., Jin, Y., Muller, J.-P., Lewis, P., Barnsley, M., Hobson, P., Disney, M., Roberts, G., Dunderdale, M., Doll, C., d'Entremont, R. P., Hu, B., Liang, S., Privette, J. L., and Roy, D.: First operational BRDF, albedo nadir reflectance products from MODIS, Remote Sens. Environ., 83, 135-148, https://doi.org/10.1016/S0034-4257(02)00091-3, 2002.

Spurr, R.: VLIDORT: A linearized pseudo-spherical vector discrete ordinate radiative transfer code for forward model and retrieval studies in multilayer multiple scattering media, J. Quant. Spectrosc. Ra., 102, 316-342, 2006.

Spurr, R. and Christi, M.: On the generation of atmospheric property Jacobians from the (V)LIDORT linearized radiative transfer models, J. Quant. Spectrosc. Ra., 142, 109-115, https://doi.org/10.1016/j.jqsrt.2014.03.011, 2014.

Spurr, R., Wang, J., Zeng, J., and Mishchenko, M. I.: Linearized T-matrix and Mie scattering computations, J. Quant. Spectrosc. Ra., 113, 425-439, https://doi.org/10.1016/j.jqsrt.2011.11.014, 2012.

Tilstra, L. G., Tuinder, O. N. E., Wang, P., and Stammes, P.: Surface reflectivity climatologies from UV to NIR determined from Earth observations by GOME-2 and SCIAMACHY, J. Geophys. Res.-Atmos., 122, 4084-4111, https://doi.org/10.1002/2016JD025940, 2017.

Tomasi, C. and Petkov, B. H.: Calculations of relative optical air masses for various aerosol types and minor gases in Arctic and Antarctic atmospheres, J. Geophys. Res.-Atmos., 119, 13631385, https://doi.org/10.1002/2013JD020600, 2014.

Torres, O., Bhartia, P. K., Herman, J. R., Ahmad, Z., and Gleason, J.: Derivation of aerosol properties from satellite measurements of backscattered ultraviolet radiation: Theoretical basis, J. Geophys. Res., 103, 17099-17110, https://doi.org/10.1029/98jd00900, 1998.

Torres, O., Ahn, C., and Chen, Z.: Improvements to the OMI near-UV aerosol algorithm using A-train CALIOP and AIRS observations, Atmos. Meas. Tech., 6, 3257-3270, https://doi.org/10.5194/amt-6-3257-2013, 2013.

Toth, T. D., Campbell, J. R., Reid, J. S., Tackett, J. L., Vaughan, M. A., Zhang, J., and Marquis, J. W.: Minimum aerosol layer detection sensitivities and their subsequent impacts on aerosol optical thickness retrievals in CALIPSO level 2 data products, Atmos. Meas. Tech., 11, 499-514, https://doi.org/10.5194/amt11-499-2018, 2018.

Vaughan, M. A., Powell, K. A., Winker, D. M., Hostetler, C. A., Kuehn, R. E., Hunt, W. H., Getzewich, B. J., Young, S. A., Liu, Z., and McGill, M. J.: Fully Automated Detection of Cloud and Aerosol Layers in the CALIPSO Lidar Measurements, J. Atmos. Ocean. Tech., 26, 2034-2050, https://doi.org/10.1175/2009jtecha1228.1, 2009.

Veefkind, J. P., Aben, I., McMullan, K., Förster, H., de Vries, J., Otter, G., Claas, J., Eskes, H. J., de Haan, J. F., Kleipool, Q., van Weele, M., Hasekamp, O., Hoogeveen, R., Landgraf, J., Snel, R., Tol, P., Ingmann, P., Voors, R., Kruizinga, B., Vink, R., Visser, H., and Levelt, P. F.: TROPOMI on the ESA Sentinel-5 Precursor: A GMES mission for global observations of the atmospheric composition for climate, air quality and ozone layer applications, Remote Sens. Environ., 120, 70-83, https://doi.org/10.1016/j.rse.2011.09.027, 2012.

Wang, J., Xu, X., Ding, S., Zeng, J., Spurr, R., Liu, X., Chance, K., and Mishchenko, M.: A numerical testbed for remote sensing of aerosols, and its demonstration for evaluating retrieval synergy from a geostationary satellite constellation of GEOCAPE and GOES-R, J. Quant. Spectrosc. Ra., 146, 510-528, https://doi.org/10.1016/j.jqsrt.2014.03.020, 2014.

Waquet, F., Cairns, B., Knobelspiesse, K., Chowdhary, J., Travis, L. D., Schmid, B., and Mishchenko, M. I.: Polarimetric remote sensing of aerosols over land, J. Geophys. Res., 114, D01206, https://doi.org/10.1029/2008jd010619, 2009.

Wendisch, M., Hellmuth, O., Ansmann, A., Heintzenberg, J., Engelmann, R., Althausen, D., Eichler, H., Müller, D., Hu, M., Zhang, Y., and Mao, J.: Radiative and dynamic effects of absorbing aerosol particles over the Pearl River Delta, China, Atmos. Environ., 42, 6405-6416, https://doi.org/10.1016/j.atmosenv.2008.02.033, 2008.

Wessel, P. and Smith, W. H. F.: A global, self-consistent, hierarchical, high-resolution shoreline database, J. Geophys. Res.-Sol Ea., 101, 8741-8743, https://doi.org/10.1029/96JB00104, 1996.

Winker, D. M., Tackett, J. L., Getzewich, B. J., Liu, Z., Vaughan, M. A., and Rogers, R. R.: The global 3-D distribution of tropospheric aerosols as characterized by CALIOP, Atmos. Chem. Phys., 13, 3345-3361, https://doi.org/10.5194/acp-133345-2013, 2013.

$\mathrm{Xu}, \mathrm{X}$. and Wang J.: Retrieval of aerosol microphysical properties from AERONET photopolarimetric measurements: 1. Information content analysis, J. Geophys. Res.-Atmos., 120, 7059-7078, 2015.

Xu, X., Wang, J., Wang, Y., Zeng, J., Torres, O., Yang, Y., Marshak, A., Reid, J., and Miller, S.: Passive remote sensing of altitude and optical depth of dust plumes using the oxygen $\mathrm{A}$ and $\mathrm{B}$ bands: First results from EPIC/DSCOVR at Lagrange-1 point, Geophys. Res. Lett., 44, 7544-7554, https://doi.org/10.1002/2017GL073939, 2017.

Xu, X., Wang, J., Wang, Y., and Kokhanovsky, A.: Chapter 1 - Passive Remote Sensing of Aerosol Height, in: Remote Sensing of Aerosols, Clouds, and Precipitation, Elsevier, Cambridge, MA, $1-22,2018 \mathrm{a}$.

Xu, X., Wang, J., Zeng, J., Hou, W., Meyer, K. G., Platnick, S. E., and Wilcox, E. M.: A pilot study of shortwave spectral fingerprints of smoke aerosols above liquid clouds, J. Quant. Spectrosc. Ra., 221, 38-50, https://doi.org/10.1016/j.jqsrt.2018.09.024, 2018b.

Yamamoto, G. and Wark, D. Q.: Discussion of the letter by R. A. Hanel, "Determination of cloud altitude from a satellite”, J. Geophys. Res., 66, 3596-3596, https://doi.org/10.1029/JZ066i010p03596, 1961.

Yang, Y., Marshak, A., Mao, J., Lyapustin, A., and Herman, J.: A method of retrieving cloud top height and cloud geometrical thickness with oxygen A and B bands for the Deep Space Climate Observatory (DSCOVR) mission: Radiative transfer simulations, J. Quant. Spectrosc. Ra., 122, 141-149, https://doi.org/10.1016/j.jqsrt.2012.09.017, 2013.

Young, S. A. and Vaughan, M. A.: The Retrieval of Profiles of Particulate Extinction from Cloud-Aerosol Lidar Infrared Pathfinder Satellite Observations (CALIPSO) Data: Al- 
gorithm Description, J. Atmos. Ocean. Tech., 26, 1105-1119, https://doi.org/10.1175/2008jtecha1221.1, 2009.

Zhang, J., Campbell, J. R., Reid, J. S., Westphal, D. L., Baker, N. L., Campbell, W. F., and Hyer, E. J.: Evaluating the impact of assimilating CALIOP-derived aerosol extinction profiles on a global mass transport model, Geophys. Res. Lett., 38, L14801, https://doi.org/10.1029/2011g1047737, 2011. 